\title{
Clinical practice guidelines of the European Association for Endoscopic Surgery (EAES) on bariatric surgery: update 2020 endorsed by IFSO-EC, EASO and ESPCOP
}

\author{
Nicola Di Lorenzo ${ }^{1}$ - Stavros A. Antoniou ${ }^{2,3}$ - Rachel L. Batterham ${ }^{4,5} \cdot$ Luca Busetto $^{6}$ - Daniela Godoroja ${ }^{7}$. \\ Angelo lossa ${ }^{8} \cdot$ Francesco M. Carrano $^{9} \cdot$ Ferdinando Agresta $^{10} \cdot$ Isaias Alarçon $^{11}$. Carmil Azran ${ }^{12}$. Nicole Bouvy ${ }^{13}$. \\ Carmen Balaguè Ponz ${ }^{14}$. Maura Buza ${ }^{15}$. Catalin Copaescu ${ }^{15}$. Maurizio De Luca ${ }^{16}$. Dror Dicker ${ }^{17}$. \\ Angelo Di Vincenzo ${ }^{6}$. Daniel M. Felsenreich ${ }^{18} \cdot$ Nader K. Francis $^{19} \cdot$ Martin Fried $^{20} \cdot$ Berta Gonzalo Prats $^{14}$. \\ David Goitein ${ }^{21,22}$. Jason C. G. Halford ${ }^{23}$. Jitka Herlesova ${ }^{20} \cdot$ Marina Kalogridaki $^{24} \cdot$ Hans Ket $^{25}$. \\ Salvador Morales-Conde ${ }^{11}$. Giacomo Piatto ${ }^{16}$. Gerhard Prager ${ }^{18}$. Suzanne Pruijssers ${ }^{13}$. Andrea Pucci ${ }^{4,5}$. \\ Shlomi Rayman ${ }^{21,22}$. Eugenia Romano ${ }^{23}$. Sergi Sanchez-Cordero ${ }^{26} \cdot$ Ramon Vilallonga $^{27} \cdot$ Gianfranco Silecchia $^{8}$
}

Received: 24 February 2020 / Accepted: 7 April 2020 / Published online: 23 April 2020

(c) The Author(s) 2020

\begin{abstract}
Background Surgery for obesity and metabolic diseases has been evolved in the light of new scientific evidence, long-term outcomes and accumulated experience. EAES has sponsored an update of previous guidelines on bariatric surgery.

Methods A multidisciplinary group of bariatric surgeons, obesity physicians, nutritional experts, psychologists, anesthetists and a patient representative comprised the guideline development panel. Development and reporting conformed to GRADE guidelines and AGREE II standards.

Results Systematic review of databases, record selection, data extraction and synthesis, evidence appraisal and evidence-todecision frameworks were developed for 42 key questions in the domains Indication; Preoperative work-up; Perioperative management; Non-bypass, bypass and one-anastomosis procedures; Revisional surgery; Postoperative care; and Investigational procedures. A total of 36 recommendations and position statements were formed through a modified Delphi procedure.
\end{abstract}

Disclaimer This clinical practice guideline has been developed under the auspice of the European Association for Endoscopic Surgery (EAES). It is intended to be used primarily by health professionals (e.g. surgeons, anesthetists, physicians) and to assist in making informed clinical decisions on diagnostic measures and therapeutic management. It is also intended to inform individual practice of allied health professionals (e.g. surgical nurses, dietitians, physical rehabilitation therapists, psychologists); to inform strategic planning and resource management by healthcare authorities (e.g. regional and national authorities, healthcare institutions, hospital administration authorities); and to inform patients wishing to obtain an overview of the condition of interest and its management. The use of recommendations contained herein must be informed by supporting evidence accompanying each recommendation and by research evidence that might not have been published by the time of writing the present document. Users must thus base their actions informed by newly published evidence at any given point

Electronic supplementary material The online version of this article (https://doi.org/10.1007/s00464-020-07555-y) contains supplementary material, which is available to authorized users.

Extended author information available on the last page of the article in time. The information in the guideline should not be relied upon as being complete or accurate, nor should it be considered as inclusive of all proper treatments or methods of care or as a statement of the standard of care. With the rapid development of scientific knowledge, new evidence may emerge between the time the guideline is developed and when it is published or read. The guideline is not continually updated and may not reflect the most recent evidence. The guideline addresses only the topics specifically identified therein and is not applicable to other interventions, diseases, or stages of diseases. This guideline does not mandate any particular course of medical care. Further, the guideline is not intended to substitute the independent professional judgment of the treating provider, as the guideline does not necessarily account for individual variation among patients. Even if evidence on a topic suggests a specific diagnostic and/or treatment action, users and especially health professionals may need to decide against the suggested or recommended action in view of circumstances related to patient values, preferences, comorbidities and disease characteristics; available human, monetary and material resources; and healthcare infrastructures. EAES provides this guideline on an "as is" basis, and makes no warranty, express or implied, regarding the guideline. 
Conclusion This document summarizes the latest evidence on bariatric surgery through state-of-the art guideline development, aiming to facilitate evidence-based clinical decisions.

Keywords Bariatric surgery · Obesity · Guidelines · EAES · GRADE · AGREE II

\section{Preamble}

It has been 14 years since EAES has launched the 2004 guidelines on obesity surgery. A lot has changed in the field since then. "Historical" techniques developed by the pioneers of bariatric surgery were virtually abandoned (e.g. vertical gastroplasty). Plenty of innovations were added to the armamentarium of healthcare professionals for the operative and perioperative management of bariatric patients. Sleeve gastrectomy, although considered experimental in 2004, has become the most common bariatric procedure. Most recent techniques, such as gastric plication, one-anastomosis bypass and endoluminal procedures are gaining increasing attention. Reiterative (redo) surgery has gained the interest of several bariatric surgeons, although clear indications and even a common definition are lacking.

guidelines. The support of the EAES Guideline Subcommittee is hereto commended.

The complex treatment of obesity and its comorbidities requires multidisciplinary integration. To this end, we invited the participation of European organizations involved in the research and management of obesity. The European Chapter of the International Federation for the Surgery of Obesity and Metabolic Disorders (IFSO-EC), the European Association for the Study of Obesity (EASO) and the European Society for the Peri-operative Care of the Obese Patient (ESPCOP) joined their forces with EAES to produce high quality work. Their representatives carried a wide variety of competencies (psychologists, obesity physicians, nutritional experts, anesthetists, laparoscopic surgeons) and comprised a concerted multidisciplinary panel. This is the first guideline with active involvement of a patient representative from the EASO patient task force.

Upon completion of the guideline manuscript, 2 prominent experts in bariatric surgery from outside Europe were invited to appraise the work against AGREE II criteria and provided their assessment with the AGREE II tool.

Finally, we are obligated to deeply thank all those who have contributed to this project, which we hope will contribute to the quality of healthcare in bariatric patients in Europe.

Nicola Di Lorenzo \& Gianfranco Silecchia

Content Coordinators

Obesity is a multifactorial disease caused by a combination of genetic, environment and metabolic factors [1]. From a public health perspective, obesity is a major risk factor
Importantly, laparoscopic surgery is now considered the gold standard approach for bariatric surgery. Under consideration of the above, these guidelines focus exclusively on minimally invasive bariatric surgery and common surgical techniques. Techniques which are now considered obsolete, although properly addressed in the previous guidelines, are not included in this update. Furthermore, the following topics are not addressed herein: modified laparoscopy (natural orifice transluminal, single-incision and robotic surgery), intragastric balloons, the impact of emerging technologies (3-D, fluorescence, hybrid) and pure metabolic surgery (without the obesity parameter).

Former standards of clinical guidance development, although of quality at the time, were replaced by the most evidence-based development and reporting standards summarized by the GRADE methodology and AGREE II

for a range of chronic diseases including type 2 diabetes, cardiovascular diseases and cancer [2].

\section{History}

The first guidelines endorsing surgery for the management of morbid obesity were published in 1991 by the US National Institutes of Health (NIH) [3]. After this first regulatory act, several international guidelines and consensus projects recommended bariatric surgery as an effective treatment of weight loss and obesity-related comorbidities.

After the introduction of laparoscopic bariatric surgery, EAES and the Society of American Gastrointestinal and Endoscopic Surgeons (SAGES) launched clinical practice guidelines in 2004 and 2008, respectively [4, 5]. The "Interdisciplinary European Guidelines" on surgery for severe obesity were published in 2008, and updated in 2014 through an expert-based consensus process $[6,7]$.

\section{Rationale and objective}

The growing burden of obesity in both industrialized and non-industrialized countries [2], the recognition of obesity as a disease in 2013 by the American Medical Association and other regulatory bodies [8], the ever-increasing research evidence in the field and the lack of recent clinical guidance, mandate an urgent need to incorporate latest evidence into clinical practice guidelines. EAES recognized this need and decided to sponsor the present update, which ultimately aims to inform healthcare in bariatric patients. 


\section{Where do these guidelines apply?}

These guidelines apply to adult (age $>18$ ) patients with body mass index $(\mathrm{BMI})>35 \mathrm{~kg} / \mathrm{m}^{2}$ who are considered fit for surgery and with no contraindications to laparoscopic surgery, unless otherwise indicated. They do not apply to the pediatric population. Healthcare systems, infrastructures, human and financial resources across European countries were considered upon developing these guidelines. Therefore, they are primarily intended to be applicable in European countries, although some recommendations might be applicable to other regions with modifications.

\section{Who are the target users?}

The present guidelines may be used by healthcare professionals, including bariatric surgeons, laparoscopic surgeons, obesity physicians, anesthetists, general practitioners, nutritional experts, psychologists, obstetrics and gynecologists, anesthetic and intensive care unit staff; and may be used as a reference to policymakers, such as European and national authorities, healthcare administrators and health insurance providers, under consideration that the external validity may vary across countries, regions and healthcare institutions.

\section{How long are these guidelines valid for?}

In view of current and ongoing research in the field, these guidelines are valid from publication up to December 2024. Target users are instructed to monitor upcoming research (research published from November 2018 onwards) which might provide evidence further supporting or even negating recommendations provided herein. For further information, see Disclaimer.

\section{Update and monitoring}

The content coordinators will monitor the literature and will recommend an update of these guidelines in 2023, unless developments in the field and emerging evidence will suggest an earlier or later update.

A web-based survey of EAES, IFSO-EC, EASO and ESPCOP is planned to be launched in October 2021 to assess guidelines use among healthcare professionals and collect feedback on implementation barriers.

\section{Material and methods}

Please see Supplementary file 1 for a detailed report of the methodology.

This guideline was developed in accordance with the GRADE methodology and complied with AGREE II guideline development and reporting standards $[9,10]$. Institutional review board approval and written consent were not required. The systematic review and synthesis of evidence conformed to PRISMA and MOOSE reporting standards, as appropriate [11, 12].

\section{Guideline development group}

The steering group consisted of bariatric surgeons, members of the EAES Consensus \& Guideline Subcommittee and a GRADE methodologist [13]. The panel was comprised of bariatric surgeons, obesity physicians, nutritional experts, psychologists, anesthetists and a patient representative ("Appendix").

\section{Topics}

PICO (Patient, Intervention, Comparator, Outcomes) questions were organized into seven domains:

1. Indication for surgery.

2. Preoperative work-up.

3. Perioperative management.

4. Bariatric procedures.

5. Revisional surgery.

6. Postoperative care.

7. Investigational procedures.

A full list of PICO questions can be found in Supplementary file 2 .

\section{Systematic review}

The literature search was confined from 2005 onwards to capture the most pertinent evidence under consideration of advances in surgical techniques, operative equipment and accumulated surgical experience, and to serve as an update of previous EAES guidelines [4]. The last search was run in November 2018. The search summary and the search syntaxes are provided in Supplementary files 3 and 4. PRISMA flow charts of record selection are provided in Supplementary file 5.

We considered meta-analyses of randomized controlled trials (RCTs), meta-analyses of cohort studies, or individual RCTs and cohort studies addressing similar PICO frameworks to those of the predefined questions. Overarching inclusion criteria across PICO questions were adult patients (age $>18$ years) with body mass index $>35 \mathrm{~kg} / \mathrm{m}^{2}$ (unless otherwise indicated) and laparoscopic surgery (in relevant topic domains). Studies addressing bariatric procedures were considered for recommendation only if they provided data on weight loss with a follow-up of at least 5 years. Animal studies, studies on pediatric patients and on robotic or open surgery were discarded. A total of 65 systematic reviews were performed. 


\section{Evidence synthesis}

In the presence of a recent meta-analysis in the context of interest, summary effect measures and interval estimates, and risk of bias parameters were considered for assessment of the quality of evidence as per GRADE methodology [9, 14]. If no recent meta-analysis was available, we searched for relevant RCTs and/or cohort studies and we extracted summary data $[15,16]$. We performed pairwise meta-analyses using a fixed or random-effects model, as appropriate. For adjustable gastric banding, we performed proportion meta-analysis to summarize the incidence of related complications and reoperations. Forest plots and funnel plots (where available) can be provided by the authors upon reasonable request.

We generated evidence tables, summarizing judgments on study design, risk of bias, inconsistency, indirectness, imprecision and the overall quality of evidence on each outcome of interest $[17,18]$.

\section{Evidence-to-decision framework}

Predefined parameters were taken into account to formulate recommendations. More specifically, importance of the problem, desirable/undesirable effects and their balance, the certainty (quality) of evidence, patient values and preferences, acceptability to key stakeholders, cost of implementation and feasibility of incorporating the intervention into practice were considered through research evidence, where available, or through panel consensus [19]. Under consideration of these parameters, the panel provided for each PICO question:

- A strong recommendation for the intervention or the comparator,

- A conditional recommendation for the intervention or the comparator, or

- No recommendation (conditional recommendation for either the intervention or the comparator) [19].

If no recommendation could be formulated on a PICO question, the panel had the option to draft a position statement. Position statements reflect the opinion of the panel, are not necessarily based upon research evidence and should not be considered formal, evidence-based recommendations.

We used the GRADEpro GDT software (enterprise version) for generation of evidence tables, development of recommendations and Delphi process. [20].

\section{Delphi process}

The recommendation drafts, along with background evidence and judgements on the above parameters, were subjected to a web-based Delphi process involving all panel members, using PanelVoice 2.0 add-on to GRADEpro. Three Delphi rounds took place overall.

\section{Survey}

Members of participating societies were surveyed to investigate the applicability of recommendations to their practice. Further, attendees of the $27^{\text {th }}$ International Congress of EAES were invited to participate in an on-site survey using a smartphone application in a dedicated session. Results of the online survey are provided in Supplementary file 6 .

\section{Appraisal}

The full guideline in its final version was reviewed by 2 prominent obesity surgeons and was appraised using the AGREE II tool. Their appraisal can be found in Supplementary file 7 .

\section{Results}

A summary list of recommendations can be found in Table 1 . The decision trees depicted in Figs. 1, 2, 3, 4, and 5 schematically summarize the recommendations.

\section{Topic 1: indication for bariatric surgery}

\section{Bariatric surgery versus medical management for morbid obesity}

\footnotetext{
Laparoscopic bariatric surgery should be considered for patients with BMI $\geq 40 \mathrm{~kg} / \mathrm{m}^{2}$ and for patients with BMI $\geq 35-40 \mathrm{~kg} / \mathrm{m}^{2}$ with associated comorbidities that are expected to improve with weight loss

Strong recommendation

Laparoscopic bariatric/metabolic surgery should be considered for patients with $\geq$ BMI $30-35 \mathrm{~kg} / \mathrm{m}^{2}$ and type 2 diabetes and/or arterial hypertension with poor control despite optimal medical therapy

Strong recommendation
}

\section{Justification}

Fifteen RCTs were identified comparing weight loss after bariatric surgery or medical therapy (5 reporting on RYGB, 3 on LAGB and the rest on mixed patient populations undergoing sleeve gastrectomy, BPD/DS, sleeve gastrectomy and/or banding) [21-35]. Random-effects meta-analysis was performed due to conceptual heterogeneity in operative interventions and nonoperative management. A RCT performed in a mixed population 
(RYGB, sleeve gastrectomy, banding) reported a weighted mean difference (WMD) of 53\% (95\% confidence interval, CI, $42 \%$ to $63 \%$ ) excess weight loss (EWL) compared to non-operative management [34]. Similarly, meta-analysis of 4 RCTs suggested a WMD of post-intervention weight of - $19 \mathrm{~kg}(95 \% \mathrm{CI}-27$ to -12 ) in favor of bariatric surgery, associated with moderate and low certainty of the evidence, respectively. These data lend support to the results of the Swedish Obese Subjects study, a large cohort study comparing bariatric surgery versus medical management in the very long term [36].

There were small or non-important differences for several metabolic surrogates. However, there was very strong association between bariatric surgery and type II diabetes (T2DM) resolution (odds ratio, OR, 29, 95\% CI 13 to 67) and moderate reduction of systolic blood pressure. These effects were observed even in RCTs enrolling patients with BMI $30-35 \mathrm{~kg} / \mathrm{m}^{2}$.

Non-operative management was associated with lower odds of complications (OR 2.44, 95\% CI 1.47 to 4.06), although authors typically did not distinguish between minor and major complications, and certainty of the evidence was very low (Supplementary Table S1). There was insufficient evidence to support cost-effectiveness of operative management, however, the panel anticipated significant savings in terms of pharmacological management of comorbidities and other medical and social interventions.

\section{Topic 2: preoperative work-up}

\section{Preoperative $H$. pylori eradication versus standard care in patients undergoing bariatric surgery}

No recommendation can be made for either routine $H$. pylori eradication or no eradication prior to bariatric surgery on the basis of available evidence. Conditional recommendation for either the intervention or the comparator

\section{Justification}

There was no direct comparative observational evidence on the effect of $H$. pylori eradication in bariatric patients. One meta-analysis of 4 observational studies comparing $H$. pyloripositive- versus $H$. pylori-negative status was identified [37]. The odds for marginal ulcer (OR $0.51,95 \%$ CI 0.03 to 8.35 ) and postoperative complications after bariatric surgery (OR 2.86, $95 \%$ CI 0.26 to 31.27 ) was similar for $H$. pylori-positiveversus $H$. pylori-negative patients, albeit interval estimates were extremely wide and uncertainty of the evidence high. Similarly, there was no firm evidence on postoperative bleeding (OR $0.90,95 \%$ CI 0.23 to 3.52) or leakage (OR 1.62, $95 \%$ CI 0.17 to 15.62 ). Another meta-analysis, yielding seven studies with 255,435 patients, found similar results [38]. Multivariable analysis of a registry cohort found $H$. pylori status to be the most important independent predictor of marginal ulceration in patients undergoing RYGB, but it had little impact on the outcome of other bariatric operations [39]. Indirectness of the evidence and imprecision of effect estimates were major parameters to judge the quality of evidence, which was very low across outcomes (Supplementary Table S2). This is reflected in a conditional recommendation for either routine eradication or alternative practice.

\section{Preoperative diet consultation versus standard care in patients undergoing bariatric surgery}

\footnotetext{
Preoperative dietitian consultation should be considered for patients undergoing bariatric surgery

Strong recommendation
}

\section{Justification}

A meta-analysis reporting 3 RCTs was found on this topic [40]. Analyses were re-performed due to error in the primary meta-analysis (calculation of WMD instead of standardized MD, SMD). The overall quality of evidence was very low for weight loss and low for postoperative complications due to risk of bias across RCTs, inconsistency (conceptual and statistical heterogeneity due to variety of preoperative interventions for weight loss, and heterogeneity in the duration of follow-up) and indirectness (follow-up duration for weight loss insufficient for generalizability of findings). Postoperative weight loss was more pronounced in the preoperative diet consultation group (SMD $0.4,95 \%$ CI 0.03 to 0.78 higher). No difference in the odds of postoperative complications was found (risk ratio, RR, $0.80,95 \%$ CI 0.22 to $2.86)$, although interval estimates were wide. Confidence in the evidence was generally low (Supplementary Table S3), however the panel favored a strong recommendation after consulting with the patient representative who expressed a strong preference for a holistic approach of the bariatric patient with continuous preoperative and postoperative consultation. The panel considered this practice feasible, requiring moderate human and financial resources, and being acceptable to stakeholders. There was no evidence of any risk for the intervention according to the panel's judgement.

\section{Preoperative endoscopy versus no endoscopy in patients undergoing bariatric surgery?}

\footnotetext{
Esophagogastroscopy can be considered as routine diagnostic test prior to bariatric surgery Conditional recommendation
} 
Table 1 Summary of recommendations

Indication for bariatric Laparoscopic bariatric surgery should be considered for patients with Strong surgery $\mathrm{BMI} \geq 40 \mathrm{~kg} / \mathrm{m}^{2}$ and for patients with BMI $\geq 35-40 \mathrm{~kg} / \mathrm{m}^{2}$ with associated comorbidities that are expected to improve with weight loss

Laparoscopic bariatric/metabolic surgery should be considered for patients with $\geq$ BMI $30-35 \mathrm{~kg} / \mathrm{m}^{2}$ and type 2 diabetes and/or arterial hypertension with poor control despite optimal medical therapy

Preoperative work-up No recommendation can be made for either routine $H$. pylori eradication or no eradication prior to bariatric surgery on the basis of available evidence

Preoperative dietitian consultation should be considered for patients undergoing bariatric surgery

Esophagogastroscopy can be considered as a routine diagnostic test prior to bariatric surgery

Psychological evaluation can be considered before bariatric surgery

A previous diagnosis of binge eating or depression may not be considered as an absolute contraindication to surgery

Perioperative manage- Screening for obstructive sleep apnea using the STOP-BANG criteria ment can be considered prior to bariatric surgery

Perioperative CPAP should be considered in patients with severe obstructive sleep apnea syndrome who are undergoing bariatric surgery

No recommendation can be made on the dose and duration of pharmacological thromboprophylaxis in patients after bariatric surgery

Inferior vena cava filter is not recommended for thromboprophylaxis in patients undergoing bariatric surgery

No recommendation for either an ERAS protocol or standard care can be made on the basis of available evidence

Perioperative multimodal analgesia with minimal opioid usage may be considered in patients undergoing bariatric surgery

Non-bypass procedures

Adjustable gastric banding surgeries are associated with a high rate of reoperations for complications or conversion to another bariatric procedure for insufficient weight loss in the long term

Sleeve gastrectomy may be preferred over adjustable gastric banding for weight loss and control/resolution of metabolic comorbidities

Sleeve gastrectomy may offer improved short-term weight loss and resolution of type 2 diabetes compared to gastric plication. No significant differences are observed at mid-term. Long-term comparative data on weight loss and metabolic effects are, however, lacking

There is insufficient evidence to recommend routine stapler line reinforcement ${ }^{\mathrm{a}}$ to reduce the leak rate

Staple line reinforcement ${ }^{\mathrm{a}}$ in sleeve gastrectomy should be considered to reduce the risk of perioperative complications ${ }^{b}$

A bougie size $<36 \mathrm{~F}$ compared to a bougie sized $\geq 36 \mathrm{~F}$ may be recommended for calibration in sleeve gastrectomy as it is associated with greater weight loss in the mid-term

More extensive antral resection $(2-3 \mathrm{~cm}$ from the pylorus versus $>5 \mathrm{~cm}$ antral preservation) potentially offers greater weight loss in the short term without a significant increase in post-operative

complications. Long term data are, however, lacking

Strong

Conditional for either intervention or comparator Strong

Conditional

Conditional

Conditional

Strong

Conditional for either intervention or comparator

Strong

Conditional for either intervention or comparator

Conditional

Position statement

Conditional

Position statement

Position statement

Strong

Conditional

Position statement 
Table 1 (continued)

\begin{tabular}{|c|c|c|}
\hline \multirow[t]{6}{*}{ Bypass procedures } & RYGB should be preferred over adjustable gastric banding & Strong \\
\hline & $\begin{array}{l}\text { RYGB results in greater weight loss and control/remission of insulin } \\
\text { resistance and type } 2 \text { diabetes compared to gastric plication }\end{array}$ & Position statement \\
\hline & $\begin{array}{l}\text { RYGB offers similar mid-term weight loss and control/remission of } \\
\text { metabolic comorbidities compared to sleeve gastrectomy. Long- } \\
\text { term comparative data are, however, lacking }\end{array}$ & Position statement \\
\hline & $\begin{array}{l}\text { RYGB can be preferred over sleeve gastrectomy in patients with } \\
\text { severe gastroesophageal reflux disease and/or severe esophagitis }\end{array}$ & Conditional \\
\hline & $\begin{array}{l}\text { No recommendation for either BPD/DS or sleeve gastrectomy can be } \\
\text { made on the basis of available comparative evidence }\end{array}$ & Conditional for either intervention or comparator \\
\hline & $\begin{array}{l}\text { With regard to mid-term weight loss there is no difference between } \\
\text { BPD/DS and RYGB. BPD/DS is superior to RYGB for control/ } \\
\text { remission of type } 2 \text { diabetes. Long-term comparative data are, how- } \\
\text { ever, lacking }\end{array}$ & Position statement \\
\hline \multirow[t]{2}{*}{$\begin{array}{l}\text { One anastomosis } \\
\text { procedures }\end{array}$} & $\begin{array}{l}\text { OAGB may offer greater short-term weight loss compared to RYGB, } \\
\text { gastric plication, adjustable gastric banding and sleeve gastrectomy. } \\
\text { Long-term comparative data are, however, lacking. The effect on } \\
\text { nutritional deficiencies remains controversial }\end{array}$ & Position statement \\
\hline & $\begin{array}{l}\text { No recommendation on SADI-S compared with OAGB, BPD/DS, } \\
\text { RYGB or sleeve gastrectomy can be made on the basis of available } \\
\text { evidence }\end{array}$ & Conditional for either intervention or comparator \\
\hline Revisional surgery & $\begin{array}{l}\text { No evidence-based criteria for indication to revisional bariatric/meta- } \\
\text { bolic surgery are available to date } \\
\text { The panel advises that the clinical decision to proceed to revisional } \\
\text { bariatric/metabolic surgery be based on a complete multidiscipli- } \\
\text { nary assessment of the patient, as recommended for the primary } \\
\text { procedure }\end{array}$ & Position statement \\
\hline \multirow[t]{6}{*}{ Postoperative care } & $\begin{array}{l}\text { Scheduled multidisciplinary post-operative follow-up should be pro- } \\
\text { vided to every patient undergoing bariatric/metabolic surgery }\end{array}$ & Strong \\
\hline & $\begin{array}{l}\text { Treatment with ursodeoxycholic acid could be considered during the } \\
\text { weight loss phase to prevent gallstones formation }\end{array}$ & Conditional \\
\hline & $\begin{array}{l}\text { Micro and/or macronutrients supplementation is recommended after } \\
\text { bariatric surgery according to the type of the procedure and to the } \\
\text { deficiencies documented during the follow-up }\end{array}$ & Strong \\
\hline & $\begin{array}{l}\text { PPI therapy should be given to patients undergoing bypass proce- } \\
\text { dures for the prevention of marginal ulcers }\end{array}$ & Strong \\
\hline & $\begin{array}{l}\text { Postoperative nutritional and behavioral advice should be provided to } \\
\text { patients undergoing bariatric surgery }\end{array}$ & Strong \\
\hline & $\begin{array}{l}\text { Pregnancy following bariatric surgery should be delayed during the } \\
\text { weight loss phase }\end{array}$ & Strong \\
\hline \multirow[t]{2}{*}{$\begin{array}{l}\text { Investigational proce- } \\
\text { dures }\end{array}$} & $\begin{array}{l}\text { For duodenal-jejunal bypass sleeves, aspiration devices, gastric } \\
\text { electrical stimulation, vagal blockade and duodenal mucosal } \\
\text { resurfacing, the quality of evidence was too low to provide any } \\
\text { recommendations }\end{array}$ & Position statement \\
\hline & $\begin{array}{l}\text { Endoluminal suturing procedures may have a role in the treatment of } \\
\text { patients with obesity with } \mathrm{BMI}<40 \mathrm{~kg} / \mathrm{m}^{2}\end{array}$ & Position statement \\
\hline
\end{tabular}

Position statements do not constitute recommendations. BMI body mass index, $C P A P$ continuous positive airway pressure, ERAS Enhanced recovery after surgery, $B P D / D S$ biliopancreatic diversion with duodenal switch, $O A G B$ one anastomosis gastric bypass, SADIS single-anastomosis duodeno-ileal switch, $P P I$ proton-pump inhibitor

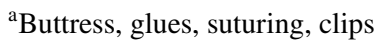

${ }^{\mathrm{b}}$ Overall mortality, bleeding 
Fig. 1 Evidence-based decision tree on the decision for bariatric surgery or conservative management. $B M I$ body mass index. BMI values are $\mathrm{kg} / \mathrm{m}^{2}$. Thick arrows and frames, and bold fonts indicate strong recommendation

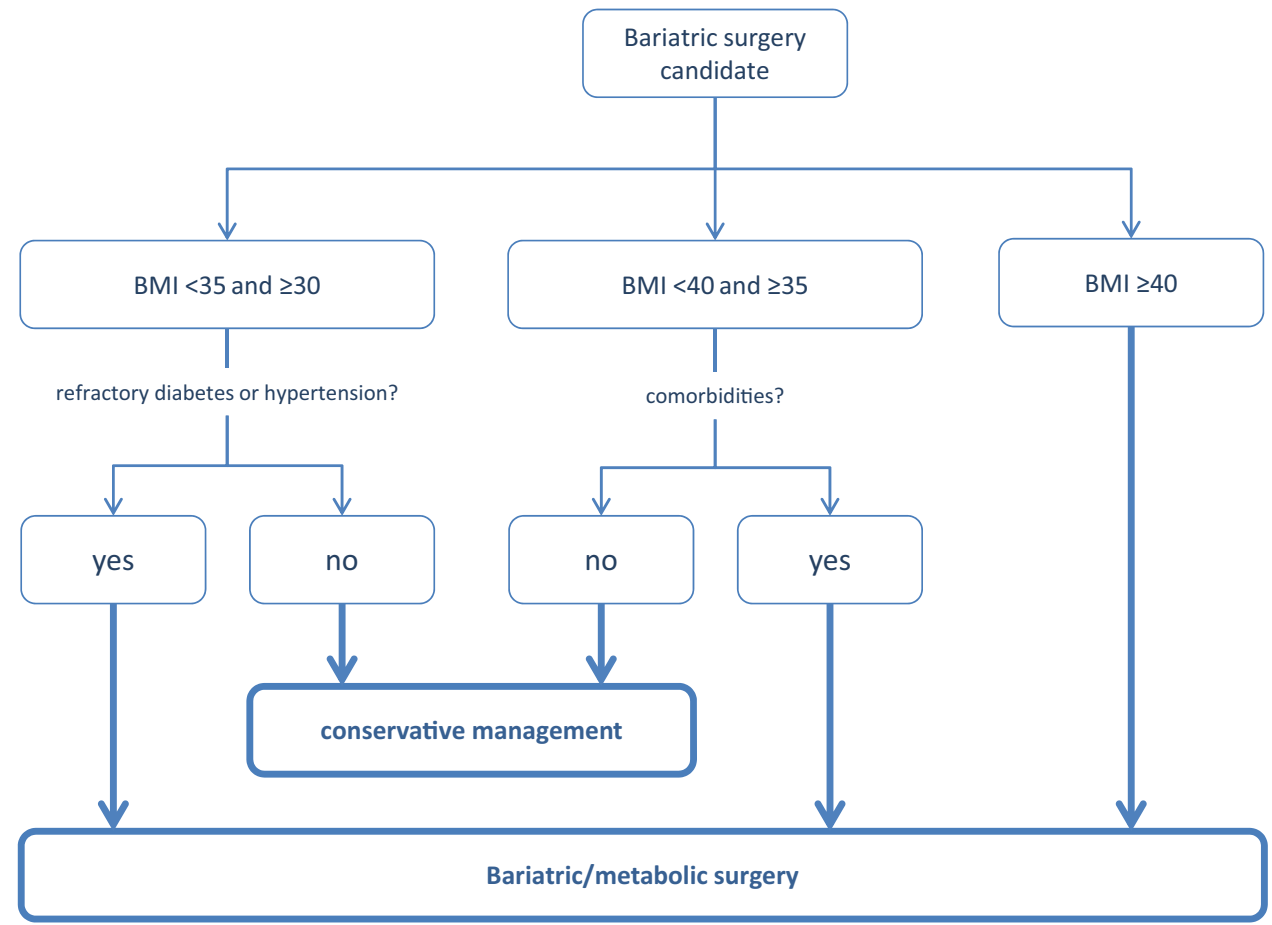

\section{Justification}

Two systematic reviews were available on this topic $[7,8$, 41, 42] Proportion meta-analyses encompassing 23 observational studies and 6845 patients suggested a summary change in surgical management after esophagogastroscopy in $7.8 \%$ (95\% CI 6.1 to $9.5 \%$ ). Changes of surgical management included: hiatal hernia repairs, delays in surgery due to gastritis or peptic ulcer disease, major changes in the planned procedure and additional endoscopic dissection for suspicious lesions. Regarding a change in medical management, proportion meta-analysis of 20 observational studies reporting on 5140 patients found a management change in $27.5 \%$ (95\% CI 20.2 to $34.8 \%$ ) after esophagogastroscopy. Changes of medical management included primarily $\mathrm{H}$. pylori eradication and initiation of proton-pump inhibitors or histamine blockers for gastritis or reflux [41]. The second meta-analysis demonstrated similar findings [42].

In view of the very low certainty owing primarily to risk of bias, inconsistency, publication bias, and questionable value in certain circumstances, hence indirectness (Supplementary Table S4), the panel provided a conditional recommendation for routine esophagogastroscopy, recognizing that selective endoscopy in patients with upper abdominal symptoms might be more appropriate.

\section{Assessment of preoperative psychological conditions versus no assessment in patients undergoing bariatric surgery}

\footnotetext{
Psychological evaluation can be considered before bariatric surgery

A previous diagnosis of binge eating or depression may not be considered as an absolute contraindication to surgery

Conditional recommendation
}

\section{Justification}

In a meta-analysis of 26 observational studies, the prevalence of mental health disorders was higher among bariatric surgery candidates compared to the general population [43]. Furthermore, preoperative depression did not seem to be associated with postoperative weight loss, whereas there was conflicting evidence on binge eating. Due to the inconsistency of evidence, the variable availability of resources, and the uncertainty of the acceptability of the intervention to stakeholders, the panel provided a conditional recommendation for psychological evaluation before bariatric surgery. However, the treating physician should be alert to identify discrete signs of psychological disorders and refer those patients for further evaluation.

Similarly, due to the uncertainty of evidence and in view of the large beneficial effects of bariatric surgery on postoperative depression (Supplementary Table S5), the panel provided a conditional recommendation for bariatric surgery in the presence of a previous diagnosis of binge eating or 


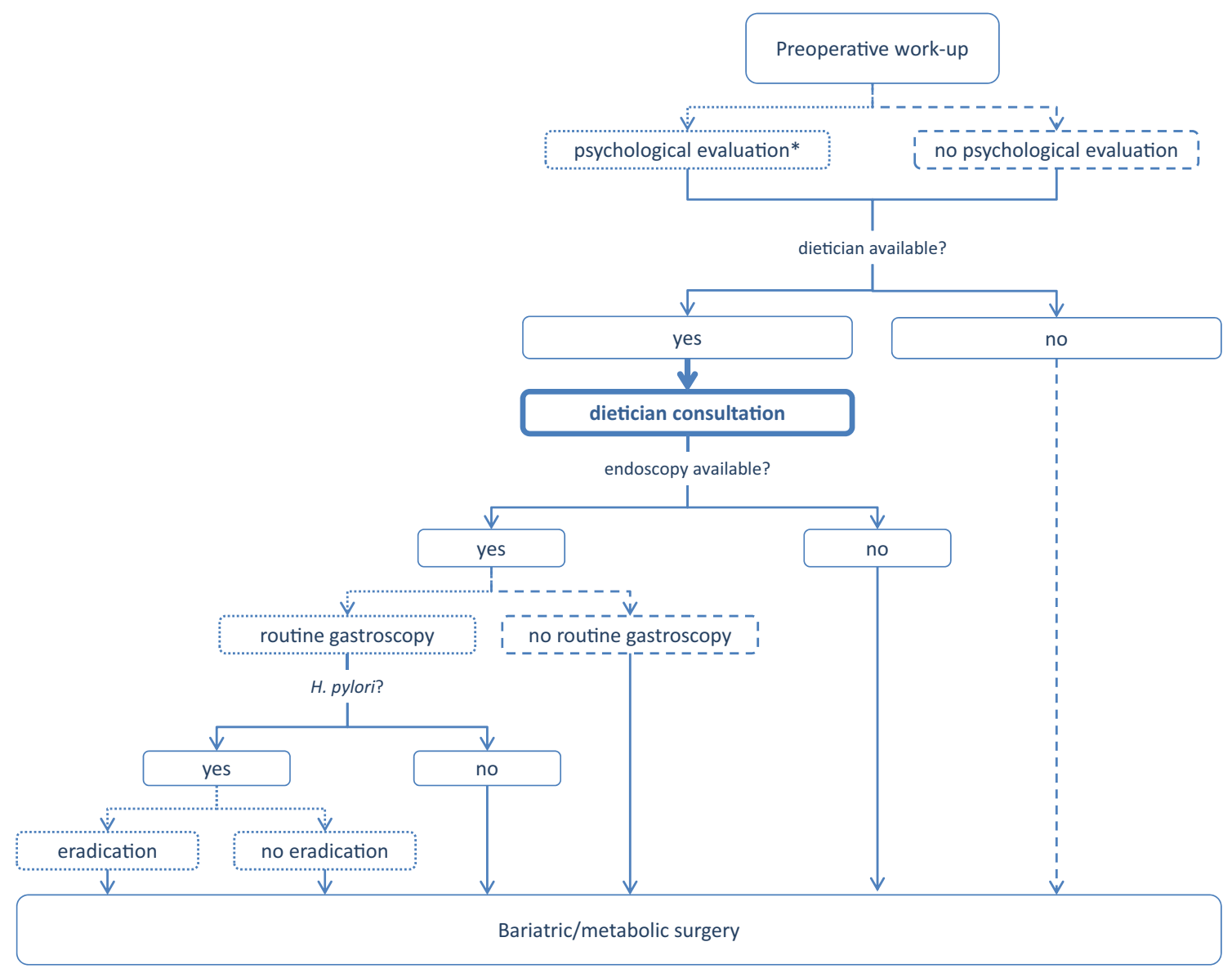

Fig. 2 Evidence-based decision tree for preoperative work-up. * Psychological evaluation should be performed when psychological disorders are suspected. Binge eating and depression might not be a contraindication for bariatric/metabolic surgery. Thick arrows

depression. It should be recognized, however, that different interventions may have various effects on patients with different psychological backgrounds. Current data do not allow subgroup analyses to account for the above. Previous evidence suggests that most mental disorders (mood, anxiety, bipolar disorder, eating disorders etc.) might be considered as a contraindication for bariatric surgery if the conditions are severe and undertreated [44].

\section{Topic 3: perioperative management}

\section{Screening versus no screening for obstructive sleep apnea in patients prior to bariatric surgery}

Screening for obstructive sleep apnea using the STOP-BANG criteria can be considered prior to bariatric surgery

Conditional recommendation and frames, and bold fonts indicate strong recommendation. Dotted arrows and frames indicate conditional recommendation for the intervention. Dashed arrows and frames indicate conditional recommendation against the intervention

\section{Justification}

No observational evidence directly addressing the question was found. Meta-analysis of observational studies suggested that patients with obstructive sleep apnea or related disorders were more likely to sustain atrial fibrillation (OR 1.51, 95\% CI 1.36 to 1.69 ) or hypoxemia (WMD $-3.8 \%, 95 \%$ CI $-5.4 \%$ to $-2.2 \%$ ) [45-59]. The latter outcome might not be clinically important, whereas the summary certainty in the evidence was very low due to risk of bias (non-controlled confounders in cohort studies), imprecision, statistical and conceptual heterogeneity (differences in definition of sleep apnea and method of diagnosis) (Supplementary Table 6). Nevertheless, screening using the STOP-BANG criteria seemed to be predictive of postoperative complications in several observational studies $[3,4,8,9,47,48,52$, 53]. There was no evidence to support cost-effectiveness of diagnosis using STOP-BANG against polysomnography, however, the panel anticipated cost savings by identifying and offering intensive care to patients at risk. The panel 
Fig. 3 Evidence-based decision tree for anesthetic and perioperative management. $C P A P$ continuous positive airway pressure, IVCF inferior vena cava filter, ERAS enhanced recovery after surgery. *with minimal use of opioids. Thick arrows and frames, and bold fonts indicate strong recommendation. Dotted arrows and frames indicate conditional recommendation for the intervention. Dashed arrows and frames indicate conditional recommendation against the intervention

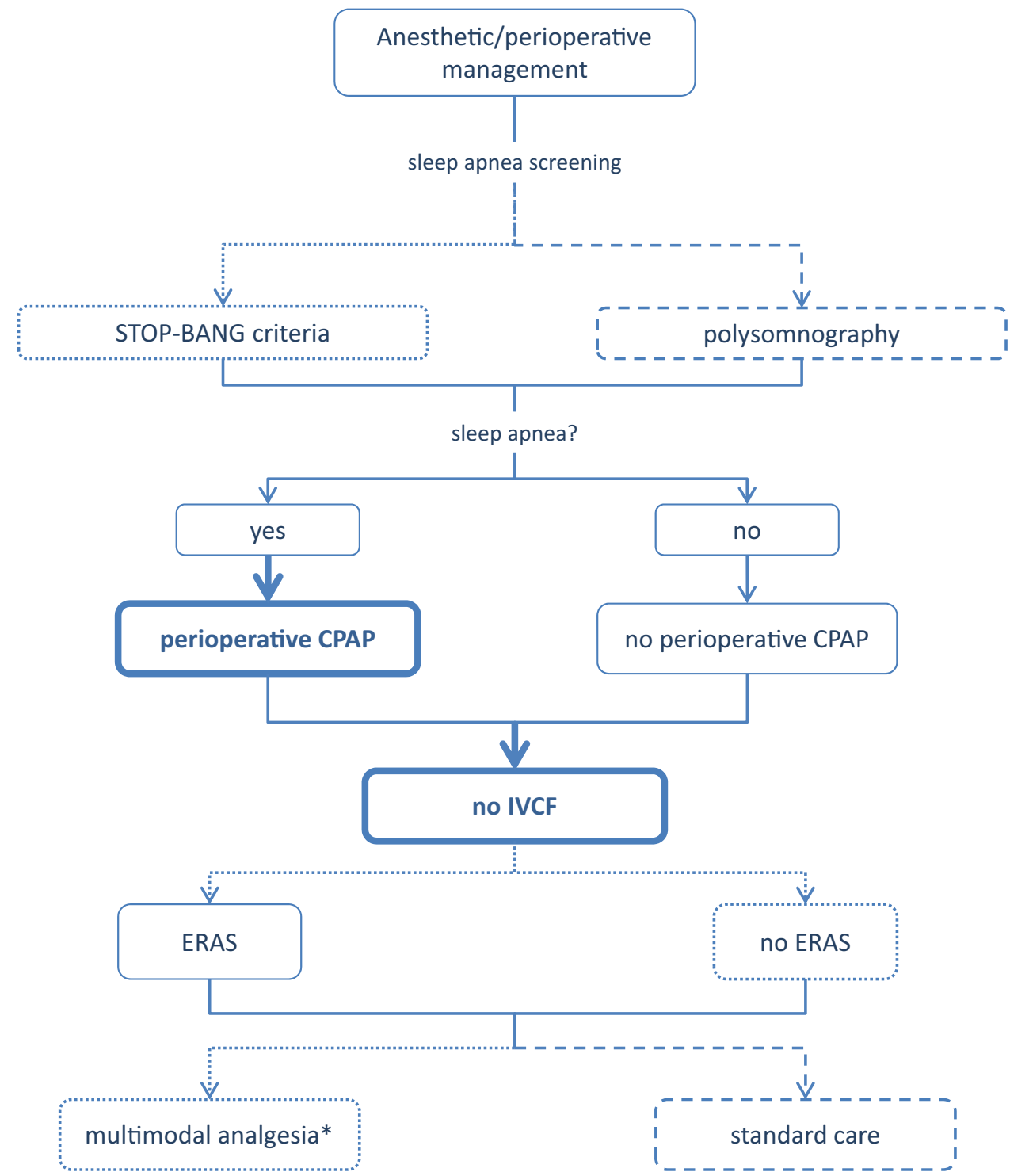

provided a conditional recommendation for using the criteria for sleep apnea screening in candidates for bariatric surgery. There was agreement that, in case of clinical suspicion of sleep apnea, formal screening be performed.

\section{Perioperative continuous positive airway pressure (CPAP) versus no CPAP in patients with severe sleep apnea syndrome}

Perioperative CPAP should be considered in patients with severe obstructive sleep apnea syndrome who are undergoing bariatric surgery

Strong recommendation
Meta-analysis of observational studies suggested higher odds of postoperative pneumonia (OR 0.24, 95\% CI 0.07 to 0.82 ), a trend towards lower odds of reintubation (OR $0.28,95 \%$ CI 0.07 to 1.04 ), and shorter hospital stay (WMD -1.6 days, $95 \%$ CI -1.83 to -1.28 ) albeit relevant evidence was of low certainty due to imprecision and the observational study design (Supplementary Table S7) [51, 52, 60, 61]. The panel provided a strong recommendation in spite of the low certainty of the evidence, due to the severity of these complications in the bariatric patient population and the low likelihood of harm associated with the intervention. 
Fig. 4 Evidence-based decision tree for the selection of operative approach. $B P D /$ $D S$ biliopancreatic diversion with duodenal switch, $A G B$ adjustable gastric banding, $G E R D$ gastroesophageal reflux disease, $R Y G B$ Roux-en-Y gastric bypass. Thick arrows and frames, and bold fonts indicate strong recommendation. Dotted arrows and frames indicate conditional recommendation for the intervention. Dashed arrows and frames indicate conditional recommendation against the intervention

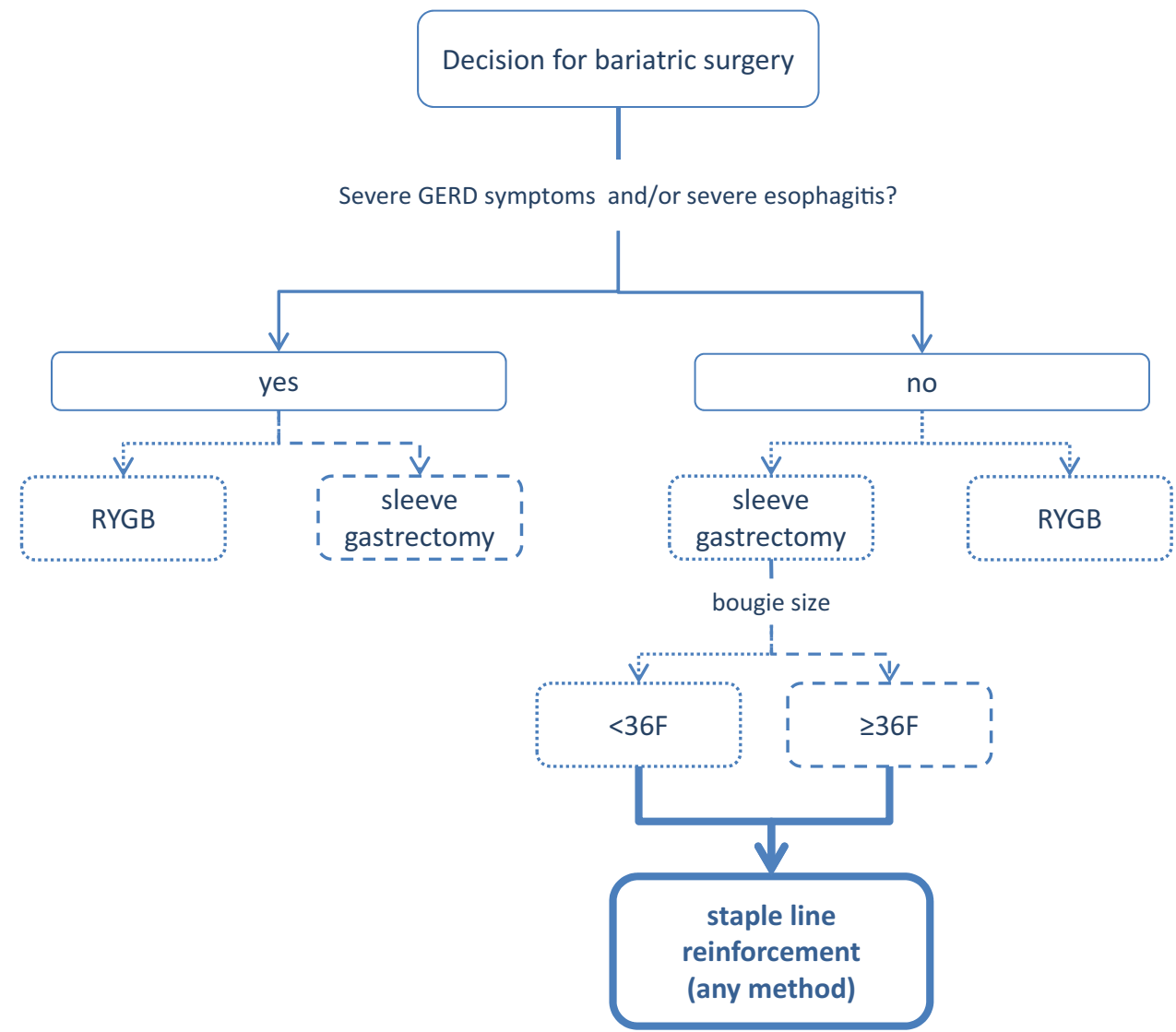

\section{High-dose versus standard-dose pharmacological antithrombotic prophylaxis after surgery}

\footnotetext{
No recommendation can be made on the dose and duration of pharmacological thromboprophylaxis in patients after bariatric surgery Conditional recommendation for either the intervention or the comparator
}

\section{Justification}

Two RCTs were identified reporting on high versus standard dose low-molecular weight heparin after bariatric surgery $[62,63]$, whereas there was no evidence on the duration of prophylaxis. Meta-analysis suggested no significant difference with regard to deep venous thrombosis or bleeding, however, relevant evidence was moderate or low, due to substantial imprecision (Supplementary Table S8). The panel provided, therefore, conditional recommendation for either high dose or standard dose prophylaxis.

\section{Inferior vena cava filter versus standard care for prevention of thromboembolic events after bariatric surgery}

\author{
Inferior vena cava filter is not recommended for thromboprophy- \\ laxis in patients undergoing bariatric surgery \\ Strong recommendation
}

Meta-analysis of six observational studies suggested higher risk of deep venous thrombosis (OR 2.81, 95\% CI 1.33 to 5.97), similar risk of pulmonary embolism (RR 1.02, 95\% CI 0.31 to 3.37 ) and a trend towards higher risk of mortality with inferior vena cava filters (RR $3.27,95 \%$ CI 0.78 to 13.64), albeit with wide interval estimates (Supplementary Table S9) [64]. Due to the importance of these outcomes and despite the low certainty of the evidence overall, this difference in effect estimates prompted the panel to provide a strong recommendation against the use of filters outside a research protocol. 


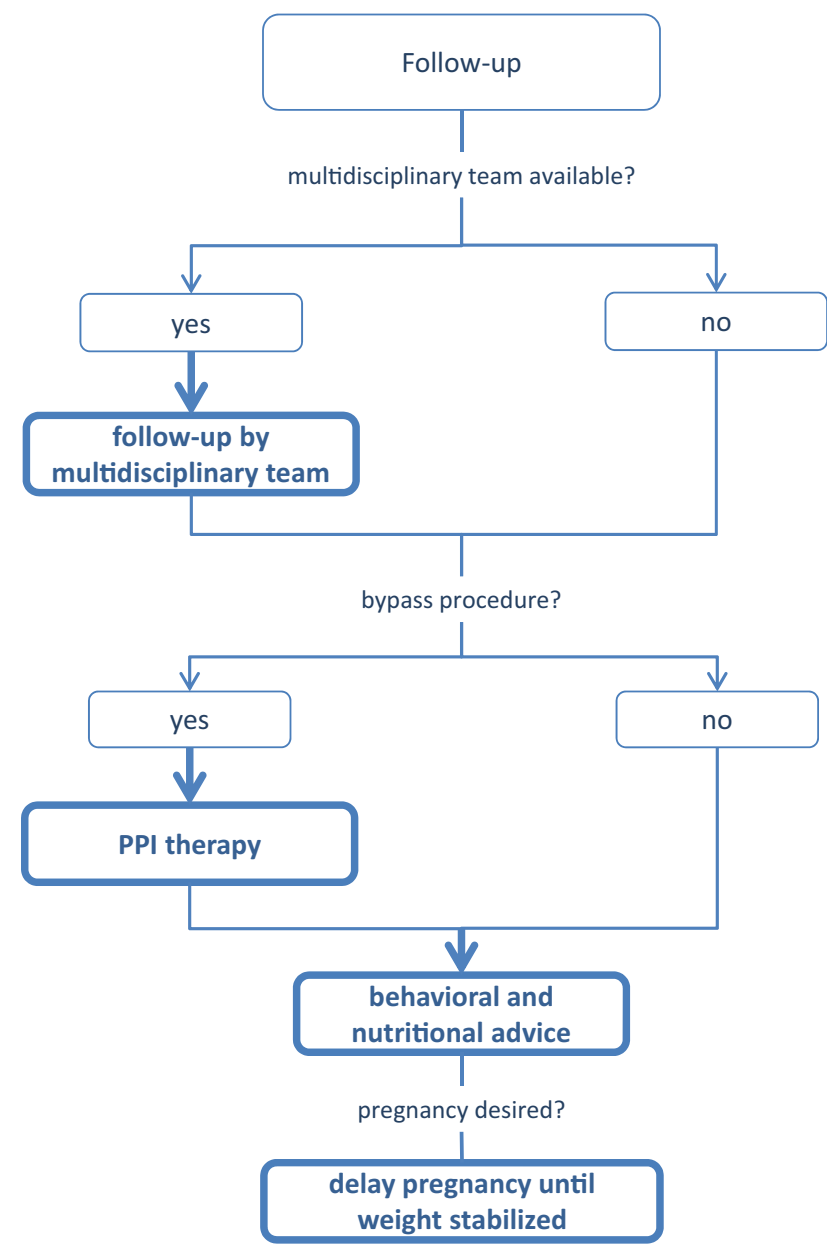

Fig. 5 Evidence-based decision tree for postoperative follow-up. PPI proton-pump inhibitor. Thick arrows and frames, and bold fonts indicate strong recommendation

\section{Enhanced recovery after surgery (ERAS) protocol versus standard care for bariatric surgery}

No recommendation for either an ERAS protocol or standard care can be made on the basis of available evidence

Conditional recommendation for either the intervention or the comparator

\section{Justification}

Two meta-analyses of 11 observational and randomized studies addressed the comparative effect of ERAS versus standard care in bariatric surgery $[1,2,65,66]$ No differences were found in major (OR $0.94,95 \%$ CI 0.58 to 1.51 ) and minor postoperative complications (OR $0.88,95 \% \mathrm{CI}$ 0.55 to 1.41 ), and mortality (RR $0.4,95 \%$ CI 0.1 to 2.2 ). Hospital stay was shorter for ERAS with a mean difference of 2.4 days $(95 \% \mathrm{CI}-3.9$ to -0.9$)$. The certainty of the evidence was very low primarily due to the observational study design, within-study risk of bias and wide interval estimates. Statistical inconsistency was also evident, probably reflecting conceptual heterogeneity of different ERAS protocols (Supplementary Table S10). In view of these findings, the panel did not favor either practice and invites further research.

\section{Multimodal analgesia with minimal use of opioids versus standard analgesia in bariatric surgery}

\footnotetext{
Perioperative multimodal analgesia with minimal opioid usage may be considered in patients undergoing bariatric surgery Conditional recommendation
}

\section{Justification}

Four observational studies and seven RCTs were identified reporting on multimodal postoperative analgesia in laparoscopic bariatric surgery [3-13, 67-76] Random-effects meta-analyses to account for conceptual heterogeneity in analgesia protocols were performed. Most outcomes were addressed by few studies, hence effect estimates were not precise. Multimodal analgesia was associated with lower visual analog scale (VAS) scores and shorter stay in a postanesthesia care unit (PACU). Of note, the odds for postoperative nausea and vomiting were lower with multimodal analgesia (OR $0.40,95 \%$ CI 0.25 to 0.64 ). There was a marginal benefit of multimodal analgesia with regard to postoperative pneumonia ( $\mathrm{RD}-0.02,95 \% \mathrm{CI}-0.05$ to 0.00 ). There was high certainty of evidence for the latter findings and very low certainty for other critical outcomes (Supplementary Table S11), which prompted the panel to provide a conventional recommendation for multimodal analgesia with minimal use of opioids. This practice may be particularly considered in patients at increased risk for opioid sensitivity and obstructive sleep apnea.

\section{Topic 4: operative procedures}

\section{Non-bypass procedures}

\section{Adjustable gastric banding}

\section{Position Statement}

Adjustable gastric banding surgeries are associated with a high rate of reoperations for complications or conversion to another bariatric procedure for insufficient weight loss in the long term 


\section{Justification}

Proportion meta-analysis of randomized and observational studies found a pooled incidence of $20 \%$ (95\% CI $13 \%$ to $26 \%$, df $=10, I^{2}=89 \%$ ) for complications requiring surgical intervention, $2 \%$ (95\% CI $1 \%$ to $3 \%$, df $=7, I^{2}=0 \%$ ) for band erosion, $7 \%$ (95\% CI $4 \%$ to $10 \%$, $\mathrm{df}=9, I^{2}=72 \%$ ) for band removal, $4 \%$ (95\% CI $3 \%$ to $\left.5 \%, \mathrm{df}=6, I^{2}=0\right)$ for port revision, and $19 \%$ (95\% CI 12 to $26 \%$, df $=8, I^{2}=85 \%$ ) for overall complications [77-89].

Four studies with a follow-up of at least 5 years were identified. Port-related and band-related complications were documented for $18 \%, 23 \%, 27 \%$ and $43 \%$ of patients [78, 80, $85,89]$. Re-interventions for insufficient weight loss were reported by 3 studies at follow-up $>5$ years, and documented for $6 \%, 12 \%$ and $18 \%$ of patients [78, 80, 85]. Port revisions occurred most commonly in the first year following surgery; reversals and conversions were more common during years 2 through 5 . In view of this cumulative evidence, the panel provided a position statement on adjustable gastric banding.

\section{Sleeve gastrectomy versus adjustable gastric banding}

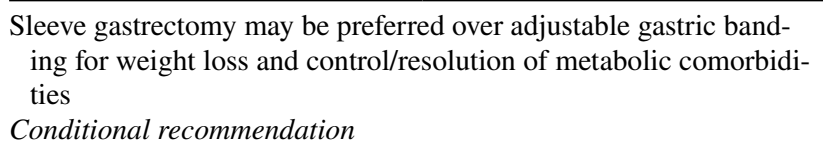

\section{Justification}

Two network meta-analyses were available reporting on weight loss and diabetes remission [90, 91]. Sleeve gastrectomy was associated with a weighted mean difference of $25 \%$ EWL (95\% CI $6.4 \%$ to $41 \%$ ) and $57 \%$ higher odds of diabetes remission (OR $0.43,95 \%$ CI 0.19 to 0.98 ). The network for weight loss was sparse with one direct and multiple indirect sources of evidence, which is the main reason for downgrading the certainty of evidence to low (Supplementary Table S12). Under consideration of the duration of follow-up (mean, 3 years, hence indirectness) and the high incidence of band-related complications, the panel provided a conditional recommendation for sleeve gastrectomy.

\section{Sleeve gastrectomy versus gastric plication}

\footnotetext{
Position statement

Sleeve gastrectomy may offer improved short-term weight loss and resolution of type 2 diabetes compared to gastric plication. No significant differences are observed at mid-term. Long-term comparative data on weight-loss and metabolic effects are, however, lacking
}

Justification

Analysis of long-term ( $\geq 5$ years) and very long-term ( $\geq 10$ years) evidence suggested an EWL between 42 and $55 \%$ with a mean weight regain between 9 and $31 \%$ for sleeve gastrectomy $[9,10,92,93]$. Comparative long-term evidence was sparse, therefore, the panel provided a position statement under consideration of short- and mid-term outcomes. Meta-analysis of summary outcomes suggests a WMD of $31 \%$ (95\% CI 10 to $72 \%$ ) in favor of sleeve gastrectomy, but higher comparative odds for postoperative complications (OR 2.86, 95\% CI 1.47 to 5.88) for the latter. Certainty of the evidence across outcomes was very low, primarily due to observational study design, inconsistency and imprecision (Supplementary Table S13).

\section{Technical considerations on sleeve gastrectomy: Staple line reinforcement}

\author{
Position statement \\ There is insufficient evidence to recommend routine stapler line \\ reinforcement* to reduce the leak rate \\ *Buttress, glues, suturing, clips,
}

Recommendation

Staple line reinforcement* in sleeve gastrectomy should be considered to reduce the risk of perioperative complications**

Strong recommendation

*Buttress, glues, suturing, clips,

**Overall mortality, bleeding

\section{Justification}

A meta-analysis of RCTs and a proportion meta-analysis addressed the topic of staple line reinforcement $[94,95]$. Staple line reinforcement was associated with a $30 \%$ lower risk for complications overall (RR 0.7, 95\% CI 0.5 to 0.9) and this finding was associated with high certainty. There was a trend towards lower risks of bleeding (RR 0.56, 95\% CI 0.25 to 1.27$)$ and leak $(0.60,95 \%$ CI 0.27 to 1.50$)$ without reaching significance, however, effect estimates were imprecise and the certainty of evidence for these outcomes downgraded (Supplementary Table S14). Under consideration of the composite parameters, the feasibility, the cost and acceptability to stakeholders, the panel unanimously supported a strong recommendation. However, it should be noted that available evidence regards buttress material, glues, suturing and clips and external validity of these findings applies only to these interventions. Furthermore, evidence on the effect of buttressing material on leak was scarce and this is reflected in the panel's position statement.

According to the Fifth International Consensus Summit on Sleeve Gastrectomy, $43 \%$ of surgeons preferred 
buttressing material for suture line reinforcement, $29 \%$ preferred oversewing and the remaining $28 \%$ did not use suture line reinforcement [96].

\section{Technical considerations on sleeve gastrectomy: Bougie size}

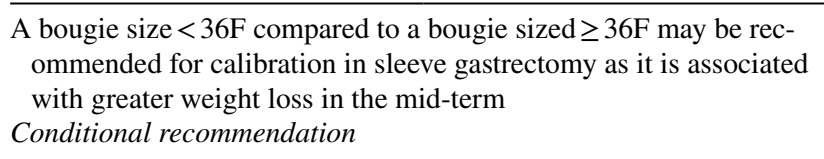

\section{Justification}

A meta-analysis of observational studies comparing sleeve gastrectomy with bougie $>36 \mathrm{~F}$ or $<36 \mathrm{~F}$ was identified [97]. The use of bougie of smaller caliber was associated with more pronounced weight loss (SMD $0.23,95 \%$ CI 0.14 to 0.33 ) and this finding was associated with moderate certainty. There was no difference in the odds for leak (OR 0.67, 95\% CI 0.67 to 1.24), overall complications (OR 1.00, 95\% CI 0.73 to 1.37 ) or gastroesophageal reflux (OR $0.77,97 \%$ CI 0.37 to 1.59 ), albeit the certainty of the evidence was very low (Supplementary Table S15). The panel provided a conditional recommendation for the use of bougie sized $<36 \mathrm{~F}$.

The Fifth International Consensus Summit survey found that bariatric surgeons tend to use a larger bougie than previously recorded, the median size being $36 \mathrm{~F}$, most probably to avoid strictures and leak associated with stricture [96]. One of the widest differences between the consensus summit report of 2011 and 2014 is that more experts believe that smaller bougies are associated with stricture and leaks, hence the tendency to use bougies of larger diameter (from $65 \%$ in 2011 to $79 \%$ in $2014, P=0.006$ ) [96].

\section{Technical considerations on sleeve gastrectomy: antral resection}

\footnotetext{
Position Statement

More extensive antral resection (2-3 cm from the pylorus versus $>5 \mathrm{~cm}$ antral preservation) potentially offers greater weight loss in the short term without a significant increase in post-operative complications. Long term data are, however, lacking
}

\section{Justification}

A meta-analysis of 6 randomized and 2 observational studies addressed this topic [98]. Weight loss was more pronounced with antral resection (SMD 0.95, 95\% CI 0.32 to 1.58), with no differences in staple line leak (RR 1.87, 95\% CI 0.46 to 7.61 ), bleeding (RR $1.27,95 \%$ CI 0.40 to 4.01 ) or gastroesophageal reflux $(0.69,95 \%$ CI 0.26 to 1.82$)$. Nevertheless, certainty in the evidence was very low across outcomes due to the observational study design, risk of bias and imprecision (Supplementary Table S16). The panel decided that there was insufficient evidence to form a recommendation and a position statement was provided instead.

In the Fourth International Consensus Summit survey, bariatric surgeons reported that they resect the antrum at $4-5 \mathrm{~cm}(32 \%), 3-4 \mathrm{~cm}(27 \%)$, or 5-6 cm (22\%) proximal to the pylorus [99].

\section{Bypass procedures}

\section{Roux-en-Y gastric bypass (RYGB) versus adjustable gastric banding}

RYGB should be preferred over adjustable gastric banding Strong recommendation

\section{Justification}

Two network meta-analyses including outcomes of pairwise comparisons addressed weight loss and diabetes remission after RYGB and adjustable gastric banding [90, 91]. The WMD of EWL was $22 \%$ (95\% CI 6.5\% to 34\%) in favor of RYGB, which was associated with high certainty evidence. There was no difference in diabetes remission (RR 1.96, 95\% CI 0.47 to 8.33 ), although certainty of the evidence was low (Supplementary Table S17). Nevertheless, mixed (direct and indirect) effect estimates were in favor of RYGB (RR 2.65, 95\% CI 1.16 to 6.07) [91]. There was no summary evidence of perioperative complications, however, the panel unanimously supported a strong recommendation for RYGB over adjustable gastric banding, as it was judged that benefits outweigh potential risks.

\section{RYGB versus gastric plication}

\author{
Position Statement \\ RYGB results in greater weight loss and control/remission of insu- \\ lin resistance and type 2 diabetes compared to gastric plication
}

\section{Justification}

Aggregate data were available for the outcome diabetes remission [91]. A network meta-analysis found RYGB to be associated with higher odds for remission compared to gastric plication (RR 4.00, 95\% CI 1.40 to 11.11 ), albeit certainty was low due to imprecision and risk of bias 
(Supplementary Table S18). Mixed effect estimates were more precise (RR 2.86, 95\% CI 1.17 to 6.98), however, still wide. The panel considered this evidence to be insufficient to form a recommendation and, in view of the scarcity of long-term data, provided a position statement instead. The statement on weight loss is based on indirect and empirical evidence suggesting a durable effect of weight loss compared to gastric plication.

\section{RYGB versus sleeve gastrectomy}

\author{
Position Statement \\ RYGB offers similar mid-term weight loss and control/remission of \\ metabolic comorbidities compared to sleeve gastrectomy. Long- \\ term comparative data are, however, lacking \\ RYGB can be preferred over sleeve gastrectomy in patients with \\ severe gastroesophageal reflux disease and/or severe esophagitis \\ Conditional recommendation
}

\section{Justification}

A meta-analysis of observational studies, two meta-analyses of RCTs and two network meta-analyses addressed the comparative outcomes of RYGB and sleeve gastrectomy [90, 91, 100-102]. There was no significant difference in EWL (WMD $-4 \%, 95 \% \mathrm{CI}-14 \%$ to $8 \%$ ) or diabetes remission (RR $0.89,95 \%$ CI 0.73 to 1.06 ), findings supported by moderate certainty of evidence. There was marginal difference in major operative morbidity (OR 2.04, 95\% CI 1.00 to 4.16), no differences in minor perioperative complications (OR $1.43,95 \%$ CI 0.60 to 3.23), and long-term minor (OR 0.64, $95 \%$ CI 0.28 to 1.47 ) or major complications (OR $0.64,95 \%$ CI 0.21 to 1.96), although the latter outcomes were associated with low or very low certainty of evidence. Remission of dyslipidemia and hypertension were in favor of sleeve gastrectomy, but certainty of the evidence was very low due to observational study design, risk of bias, inconsistency and indirectness (Supplementary Table S19).

Two RCTs addressed gastroesophageal reflux after RYGB and sleeve gastrectomy [103, 104]. Remission of pre-existing gastroesophageal reflux (absolute difference $-0.36,95 \%$ CI -0.57 to -0.15 ) and de novo gastroesophageal reflux was more often seen after sleeve gastrectomy (absolute difference $-0.31 \%, 95 \% \mathrm{CI}-0.08 \%$ to $-0.54 \%$ ) (moderate and low certainty of evidence). Under consideration of the low certainty of evidence in important outcomes and the lack of long-term ( $>5$ years) data, the panel provided a position statement on the comparative effect in the general bariatric population and a conditional recommendation for patients with reflux disease.

\section{Biliopancreatic diversion with duodenal switch (BPD/DS) versus sleeve gastrectomy}

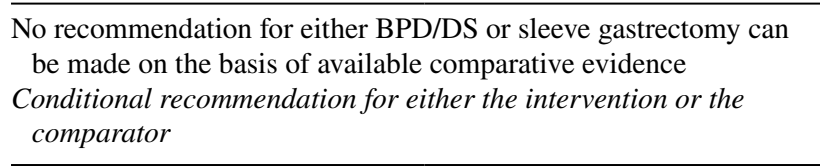

Justification

Evidence on BPD/DS was very scarce, probably due to limited diffusion of this technique in bariatric surgeons [105]. Only 2 cohort studies were identified, which addressed morbidity and mortality [106, 107]. Effect estimates was summarized with meta-analysis, however, the certainty of evidence was very low due to imprecision (Supplementary Table S20). As such, the panel did not provide a recommendation for BPD/DS or sleeve gastrectomy.

\section{BPD/DS versus RYGB}

Position Statement

With regard to mid-term weight loss there is no difference between BPD/DS and RYGB. BPD/DS is superior to RYGB for control/ remission of type 2 diabetes. Long-term comparative data are, however, lacking

\section{Justification}

Four RCTs were identified and outcomes were meta-analyzed [27, 108-110]. Despite low risk of bias across trials, effect estimates were imprecise and indirectness significant, because no long-term data were available. EWL was similar (WMD 14\%, 95\% CI - 12.21 to 42.15 , very low certainty), whereas long-term morbidity (OR 3.38, 95\% CI 1.14 to 10.05 , low certainty) and diabetes remission (OR 8.06, 95\% CI 1.35 to 48.14) were in favor of RYGB (Supplementary Table S21).

A matched cohort study on 73,702 patients from the Bariatric Outcomes Longitudinal Database reported BPD/DS to be associated with the greatest adjusted change in BMI compared to RYGB and sleeve gastrectomy. The study also suggested that BPD/DS was superior in terms of diabetes remission [111].

Due to conflicting evidence and generally low certainty across outcomes, no recommendation was provided by the panel. 


\section{One anastomosis procedures}

\section{One anastomosis gastric bypass (OAGB)}

\author{
Position Statement \\ OAGB may offer greater short-term weight loss compared to \\ RYGB, gastric plication, adjustable gastric banding and sleeve \\ gastrectomy. Long-term comparative data are, however, lacking. \\ The effect on nutritional deficiencies remains controversial
}

\section{Justification}

OAGB is an emerging bariatric procedure which gains increasing interest among bariatric surgeons. According to the First IFSO Consensus Statement, the panel unanimously supported that OAGB is an acceptable mainstream surgical option and $96 \%$ considered that it may no longer be regarded as new or experimental procedure [112].

As a recently developed procedure, relevant evidence was limited. Certainty of the evidence was moderate across most outcomes for the comparison OAGB versus RYGB with only 2 RCTs, which were meta-analyzed, and a network metaanalysis addressing the comparison $[91,113,114]$.Quality of life and resolution of comorbidities was similar. OAGB was associated with marginally reduced odds for in-hospital morbidity (OR $0.38,95 \%$ CI 0.13 to 1.14 ) and late complications $(0.76,95 \%$ CI 0.33 to 1.77$)$ at the expense of less pronounced EWL (WMD 13\%, 95\% CI $2 \%$ to $29 \%$; very low certainty) (Supplementary Table S22).

A meta-analysis of four observational studies compared AGB with one anastomosis gastric bypass (OAGB) [115]. OAGB was associated with lower postoperative BMI (WMD $-7 \mathrm{~kg} / \mathrm{m}^{2}, 95 \% \mathrm{CI}-9$ to -4$)$ and smaller waist circumference (WMD $-14 \mathrm{~cm}, 95 \% \mathrm{CI}-27$ to -1 ), whereas there was no difference in diabetes remission (RR $1.48,95 \%$ CI 0.98 to 2.25 ) at a mean follow-up of 1 year (Supplementary Table S23).

Two meta-analyses addressed the comparison OAGB versus sleeve gastrectomy $[116,117]$. As they combine randomized and observational data, we meta-analyzed RCTs only to increase certainty in the evidence, when possible $[114,118]$. EWL was more pronounced with sleeve gastrectomy (WMD 20\%, 95\% CI 20 to 23) and this finding was supported with high certainty in the evidence. The analysis favored sleeve gastrectomy in terms of diabetes and dyslipidemia remission and there was a trend towards lower odds for morbidity for OAGB (OR $0.67,95 \%$ CI 0.28 to 1.61 ) (Supplementary Table S24). One RCT compared OAGB versus gastric plication, which provided very limited evidence (Supplementary Table S25) [119].

Under consideration of the lack of long-term data, the panel provided a position statement and no recommendation.

\section{Single anastomosis duodeno-ileal bypass withsleeve gastrectomy (SADI-S)}

\author{
No recommendation on SADI-S compared with OAGB, BPD/DS, \\ RYGB or sleeve gastrectomy can be made on the basis of avail- \\ able evidence \\ Conditional recommendation for either the intervention or the \\ comparator
}

\section{Justification}

SADI-S represents a simplified modification of the BPD/DS. There was limited evidence across comparisons.

One observational study investigated the comparative effect of SADI-S and RYGB, providing very low certainty evidence (Supplementary Table S26) [120]. Similarly, one observational study addressed SADI-S versus BPD/DS (Supplementary Table S27) and one addressed SADI-S versus sleeve gastrectomy (Supplementary Table S28) [121, 122].

\section{Topic 5: revisional surgery}

\section{Position Statement \\ No evidence-based criteria for indication to revisional bariatric/ metabolic surgery are available to date \\ The panel advises that the clinical decision to proceed to revisional bariatric/metabolic surgery be based on a complete multidiscipli- nary assessment of the patient, as recommended for the primary procedure}

\section{Terminology}

The increasing use of bariatric/metabolic surgery was accompanied by a parallel increase of the number of patients who received an additional bariatric procedure after the index one [123]. In 2014, the American Society for Metabolic \& Bariatric Surgery performed a systematic review on re-operative bariatric surgery and proposed a nomenclature for dividing the secondary procedures based on the technical aspects (Supplementary Table S29) [124].

Reoperations after bariatric surgery may be primarily performed for two reasons: (a) to solve or fix complications or side effects linked to the primary procedures; (b) to improve the results in patients with insufficient weight loss, continued or poorly controlled comorbid disease, or weight regain. We suggest the use of the term revisional bariatric/metabolic surgery only for re-operative procedures performed for the second group of indications. Revisional surgery can correct or convert the primary procedure. The surgical procedures targeting the first category of indications are re-interventions indicated by the patient's medical condition, performed 
electively or in emergency, and they can include conversions, corrective or reversal procedures.

Severe obesity is a chronic disease that requires lifetime treatment. While bariatric/metabolic surgery is usually an effective and durable therapy, there will be patients who respond well to the initial therapy and others with only partial response, as in many other chronic diseases requiring medical or surgical therapy. There will be also a subset of patients having recurrent or persistent disease. These patients may require escalation of therapy or a new treatment modality [124]. We, therefore, suggest that the term "failure" or "failed" in respect to metabolic/bariatric procedures be abandoned. The term "non-responders" should be adopted because it is more consistent with the frame of obesity as chronic disease.

\section{Clinical indications for revisional surgery}

We define as revisional bariatric/metabolic surgery any re-operative bariatric procedure performed to improve the results in patients with insufficient weight loss, continued comorbid disease, or weight regain. However, an established consensus on which levels of insufficient weight loss or weight regain should be considered as indicators for the need of a revisional procedure is still lacking.

Bonouvrie et al. recently performed a systematic review illustrating the lack of standard definitions of non-responders after bariatric surgery [125]. This is partly due to heterogeneity among studies which precludes evidence synthesis for revisional surgery. There is an urgent need to introduce standard definitions to be used in future research and clinical practice. Current definitions remain arbitrary, due to the lack of solid evidence in this field. A set of diagnostic criteria is proposed in Supplementary Table S30, taking into consideration current indications for bariatric/metabolic surgery and the evidence on the positive effects of a $10 \%$ weight loss [126].

\section{Work-up in case of revisional surgery}

Current evidence suggests that revisional surgery may confer an improvement of obesity and obesity-related comorbidities in patients without optimal results after an index procedure. Escalation of therapy in patients with poor response should be considered rational in the long-term management of a chronic disease such as obesity [124]. On the other hand, revisional bariatric surgery confers a higher risk of perioperative complications than primary bariatric surgery [127]. The individual risk/benefit analysis for revisional surgery is, therefore, even more complex than for index procedures. We suggest that the clinical decision to proceed to revisional bariatric surgery be based on a complete multidisciplinary assessment, as recommended for the primary procedure, including endoscopic and radiological studies, with detailed information about the index procedure and proper evaluation of nutritional and behavioral status.

\section{Topic 6: postoperative care}

\section{Scheduled multidisciplinary post-operative follow-up versus standard care}

\author{
Scheduled multidisciplinary post-operative follow-up should be \\ provided to every patient undergoing bariatric/metabolic surgery \\ Strong recommendation
}

\section{Justification}

A meta-analysis of summary data from five RCTs reporting patients undergoing a variety of bariatric procedures and assessing the impact of scheduled multidisciplinary postoperative follow-up versus standard care reported more pronounced weight loss in the treatment group [128]. Scheduled multidisciplinary post-operative follow-up resulted in slightly greater EWL (WMD $1.6 \%, 95 \%$ CI $0.82 \%$ to $2.38 \%$ ) compared to the control group (Supplementary Table S31). Despite this marginal effect and the low certainty in the evidence because of risk of bias and inconsistency, the panel provided a strong recommendation after consulting with the patient representative, who expressed a strong preference for close continuous preoperative and postoperative consultation. The panel considered this practice feasible, requiring moderate human and financial resources, and being acceptable to stakeholders. There was no evidence of any risk for the intervention according to the panel's judgement.

\section{Treatment with ursodeoxycholic acid during the weight loss phase following bariatric surgery}

Treatment with ursodeoxycholic acid could be considered during the weight loss phase to prevent gallstones formation Conditional recommendation

\section{Justification}

A meta-analysis of 6 RCTs and two observational studies found that ursodeoxycholic acid treatment versus no treatment was associated with lower odds of gallstone formation (OR $0.20,95 \%$ CI 0.13 to 0.33 ) [129]. Due to mixed randomized and observational study design, substantial risk of bias and publication bias, certainty in the evidence was very low (Supplementary Table S32). Under consideration of the 
low-risk profile and the low cost of the intervention, the panel provided a conditional recommendation, recognizing, however, that further research is warranted.

\section{Supplementation of micro and/or micronutrients after bariatric surgery}

Micro and/or macronutrients supplementation is recommended after bariatric surgery according to the type of the procedure and to the deficiencies documented during the follow-up

Strong recommendation

\section{Justification}

Studies reporting micro and/or macronutrients supplementation post-surgery are limited. One meta-analysis of $5 \mathrm{RCTs}$ and 7 observational studies was identified, which evaluated the effect of vitamin D supplementation on preventing Vitamin D deficiency [130]. Vitamin D deficiency was more common in the no supplementation group (OR 3.82, 95\% CI 1.70 to 8.57 ) (Supplementary Table S33). Despite the sparse evidence, the panel decided to provide a strong recommendation, as it considered that the anticipated benefits outweigh the potential risks of such practice.

\section{Proton-pump inhibitor (PPI) therapy after bariatric surgery for the prevention of marginal ulcers}

\footnotetext{
PPI therapy should be given to patients undergoing bypass procedures for the prevention of marginal ulcers Strong recommendation
}

\section{Justification}

A meta-analysis of three cohort studies that compared the comparative effect of PPIs on marginal ulcers suggested beneficial effect of PPI treatment (OR $0.50,95 \%$ CI 0.29 to 0.90, moderate certainty) (Supplementary Table S34) [131]. Under consideration of the risk/benefit ratio, the low cost and acceptability of the intervention, the panel provided a strong recommendation.

\section{Postoperative nutritional and behavioral advice versus standard care}

\footnotetext{
Postoperative nutritional and behavioral advice should be provided to patients undergoing bariatric surgery

Strong recommendation
}

\section{Justification}

Evidence supporting the need for postoperative nutritional and behavioral counseling is supported by a meta-analysis of 6 RCTs [132]. At 12-moth follow-up, the WMD of EWL was $11 \%$ (95\% CI $3 \%$ to $19 \%$ ) in favor of the intervention. Certainty of the evidence was, however, very low, due to risk of bias, inconsistency and indirectness because of the variety of interventions (Supplementary Table S35). Under consideration of patient preferences and the anticipated feasibility and moderate resources, the panel supported a strong recommendation.

\section{Delaying pregnancy following bariatric surgery until after the weight loss phase versus no delay on fetal complications}

\author{
Pregnancy following bariatric surgery should be delayed \\ during the weight loss phase \\ Strong recommendation
}

\section{Justification}

Six observational studies reporting fetal outcomes following pregnancy after bariatric surgery were identified and a meta-analysis comparing early pregnancy versus delayed pregnancy was undertaken [133-138]. Delaying pregnancy was associated with a trend towards lower odds for admission in the neonatal intensive care unit (OR 0.73, 95\% 0.45 to 1.18). There were no further substantial findings, however, certainty was very low across outcomes (Supplementary Table S36). Despite this sparsity of evidence, the panel considered prudent to provide a strong recommendation for delaying pregnancy during the weight loss phase to avoid fetal complications that may not have been captured by current studies.

\section{Topic 7: investigational procedures}

\section{Position statement}

For duodenal-jejunal bypass sleeves, aspiration devices, gastric electrical stimulation, vagal blockade and duodenal mucosal resurfacing, the quality of evidence was too low to provide any recommendations 
Endoluminal suturing procedures may have a role in the treatment of obese patients with BMI below $40 \mathrm{~kg} / \mathrm{m}^{2}$

\section{Justification}

Evidence was limited for emerging bariatric interventions and long-term data were not available. A meta-analysis of four RCTs that compared EndoBarrier ${ }^{\circledR}$ with non-surgical management was identified [139]. EWL was 36.9\% (95\% CI $29 \%$ to $45 \%$ ) at 1-year follow-up (moderate certainty, Supplementary Table S37). EndoBarrier® was reported to be associated with $15.7 \%$ severe adverse events [139].

One RCT has compared AspireAssist ${ }^{\circledR}$ with lifestyle interventions and 1-year follow-up [140]. The WMD of EWL was $22 \%$ (95\% CI $14 \%$ to $30 \%$ ), HbAlc improvement was minimal (WMD $0.14 \%, 95 \%$ CI $0 \%$ to $0.28 \%$ ), whereas evidence on morbidity was associated with low certainty (Supplementary Table S38). No severe complications were reported.

Three cohort studies reported on the abiliti ${ }^{\circledR}$ device and 1-year follow-up [141-143]. EWL ranged from 28.7 to 49.3\%. Few self-limiting adverse events were reported and $2 \%$ severe adverse events. Certainty of the evidence was, however, very low.

Two RCTs assessing the effect of vBloc ${ }^{\circledR}$ reported 17\% and $24 \%$ EWL at 1-year follow-up [144, 145]. Two-year follow-up suggested sustained weight loss [146, 147]. The technical difficulty of the procedure and a high rate of severe adverse events are significant drawbacks to this intervention.

One cohort study reported on duodenal mucosal resurfacing, relevant evidence being very low [148]. Two RCTs and 1 cohort study investigated the effect of the Pose ${ }^{\circledR}$ procedure and reported EWL between 16-45\% [149-151]. The procedure safety profile seems acceptable, however certainty in the evidence was very low.

Five observational studies have addressed the use of OverStitch $^{\mathrm{TM}}$ [152-156]. The procedure may be considered safe, well tolerated and effective with a mean EWL of 50\% at 1 year. Evidence suggests durability of plications and progressive weight loss up to 2 years.

\section{Comments}

\section{Survey results}

The guideline development group aimed to investigate whether recommendations and position statements are applicable and can be transferred to individuals' clinical practice. Indeed, one of the AGREE II domains is focused on the applicability of the guideline in the practice of target users. The rationale was therefore both to assess the clinical merit of the recommendations (as an aspect of external validity) and to inform the topics of future updates.

A total of 220 professionals involved in the management of patients with obesity responded to the 38 survey questions. The majority of survey participants were surgeons. Specifically, bariatric surgeons accounted for $61 \%$ of the total and $62 \%$ of participants worked in high volume bariatric centers (defined as $>50$ bariatric procedures per year).

The majority of recommendations were considered applicable to participants' practice. Among those where applicability was judged as low, was the recommendation on routine H. pylori eradication. This may be due to the fact that preoperative esophagogastroscopy is not considered standard preoperative study in many centers. Neutral recommendations were considered, as expected, to be not applicable by a substantial proportion of participants.

\section{Implications for future actions}

The present guidelines summarize pertinent evidence in the field of bariatric surgery. Despite the advances in the field, we have identified several gaps, particularly in the long-term reporting of outcomes [90, 91]. Furthermore, we have identified only two network meta-analyses, which reported several outcomes of interest. Considering the variety of treatment options, network meta-analysis is the optimal method to summarize evidence across interventions in the same metaanalytical model and is undoubtedly a prosperous field of research.

Follow-up reports of emerging procedures, such as OAGB, and further, large-scales RCTs on investigational procedures, with robust methodology are eagerly awaited. As the incidence of obesity increases in societies with a high prevalence of psychological disorders, further investigation on the indications for bariatric surgery is warranted. Furthermore, obesity is an emerging problem in developing countries and, as such, healthcare authorities are called to promote health equity by ensuring access to healthcare for underprivileged and vulnerable populations.

\section{Conclusions}

Evidence from clinical research suggests that bariatric surgery is highly effective in the management of obesity. This document summarizes the latest evidence on bariatric surgery. It was developed in compliance with state-of-the art methodological principles to reliably appraise evidence, hereby facilitating evidence-based clinical decisions and informing authoritative actions of policymakers and other stakeholders. 
Acknowledgements We would like to thank Prof. Lilian Kow, President of IFSO and Director of the Adelaide Bariatric Centre; and Prof. Scott Shikora, Director of the Center for Metabolic and Bariatric Surgery at Brigham and Women's Hospital and Professor of Surgery at Harvard Medical School, President Elect of IFSO for their external review of these guidelines. The input of Mr. Carlos Oliveira as patient representative is greatly appreciated. We would like to extend our special thanks to Zbigniew Leś for kindly providing a trial version of GRADEpro for enterprises, including PanelVoice 2.0.

Author contributions I confirm that authors of the manuscript SENDD-20-00157 fulfill the ICMJE authorship criteria (http://www.icmje. org/recommendations/browse/roles-and-responsibilities/defining-therole-of-authors-and-contributors.html) and have contributed to the submitted work as follows: NDL: Conception and design, interpretation of data, drafting the work, final approval of the version to be published, agreement to be accountable for all aspects of the work. SAA: Conception and design, analysis and interpretation of data, drafting the work, final approval of the version to be published, agreement to be accountable for all aspects of the work. RLB: Interpretation of data, critical revision for important intellectual content, final approval of the version to be published, agreement to be accountable for all aspects of the work. LB: Interpretation of data, critical revision for important intellectual content, final approval of the version to be published, agreement to be accountable for all aspects of the work. DG: Acquisition, analysis and interpretation of data, critical revision for important intellectual content, final approval of the version to be published, agreement to be accountable for all aspects of the work. AI: Acquisition and analysis of data, drafting the work, final approval of the version to be published, agreement to be accountable for all aspects of the work 2. FMC: Acquisition and analysis of data, drafting the work, final approval of the version to be published, agreement to be accountable for all aspects of the work. FA: Interpretation of data, critical revision for important intellectual content, final approval of the version to be published, agreement to be accountable for all aspects of the work. IA: Acquisition and analysis of data, drafting the work, final approval of the version to be published, agreement to be accountable for all aspects of the work. CA: Acquisition and analysis of data, drafting the work, final approval of the version to be published, agreement to be accountable for all aspects of the work. NB: Interpretation of data, critical revision for important intellectual content, final approval of the version to be published, agreement to be accountable for all aspects of the work. MCBP: Interpretation of data, critical revision for important intellectual content, final approval of the version to be published, agreement to be accountable for all aspects of the work. MB: Acquisition and analysis of data, drafting the work, final approval of the version to be published, agreement to be accountable for all aspects of the work. CC: Interpretation of data, critical revision for important intellectual content, final approval of the version to be published, agreement to be accountable for all aspects of the work. MDL: Interpretation of data, critical revision for important intellectual content, final approval of the version to be published, agreement to be accountable for all aspects of the work 3. DD: Interpretation of data, critical revision for important intellectual content, final approval of the version to be published, agreement to be accountable for all aspects of the work. ADV: Acquisition and analysis of data, drafting the work, final approval of the version to be published, agreement to be accountable for all aspects of the work. DMF: Acquisition and analysis of data, drafting the work, final approval of the version to be published, agreement to be accountable for all aspects of the work. NKF: Interpretation of data, critical revision for important intellectual content, final approval of the version to be published, agreement to be accountable for all aspects of the work. MF: Interpretation of data, critical revision for important intellectual content, final approval of the version to be published, agreement to be accountable for all aspects of the work. BGP: Acquisition and analysis of data, drafting the work, final approval of the version to be published, agreement to be accountable for all aspects of the work. DG: Interpretation of data, critical revision for important intellectual content, final approval of the version to be published, agreement to be accountable for all aspects of the work. JCGH: Interpretation of data, critical revision for important intellectual content, final approval of the version to be published, agreement to be accountable for all aspects of the work 4 Jitka Herlesova: Acquisition and analysis of data, drafting the work, final approval of the version to be published, agreement to be accountable for all aspects of the work. MK: Acquisition, analysis and interpretation of data, critical revision for important intellectual content, final approval of the version to be published, agreement to be accountable for all aspects of the work. HK: Acquisition of data, critical revision for important intellectual content, final approval of the version to be published, agreement to be accountable for all aspects of the work. SM-C: Interpretation of data, critical revision for important intellectual content, final approval of the version to be published, agreement to be accountable for all aspects of the work. GP: Acquisition and analysis of data, drafting the work, final approval of the version to be published, agreement to be accountable for all aspects of the work. GP: Interpretation of data, critical revision for important intellectual content, final approval of the version to be published, agreement to be accountable for all aspects of the work. SP: Acquisition and analysis of data, drafting the work, final approval of the version to be published, agreement to be accountable for all aspects of the work. AP: Acquisition and analysis of data, drafting the work, final approval of the version to be published, agreement to be accountable for all aspects of the work. SR: Acquisition and analysis of data, drafting the work, final approval of the version to be published, agreement to be accountable for all aspects of the work 5. ER: Acquisition and analysis of data, drafting the work, final approval of the version to be published, agreement to be accountable for all aspects of the work. SS-C: Acquisition and analysis of data, drafting the work, final approval of the version to be published, agreement to be accountable for all aspects of the work. RV: Interpretation of data, critical revision for important intellectual content, final approval of the version to be published, agreement to be accountable for all aspects of the work. GS: Conception and design, interpretation of data, drafting the work, final approval of the version to be published, agreement to be accountable for all aspects of the work.

Funding This work was funded by the European Association for Endoscopic Surgery (EAES). The funding body did not have any influence on the content of this work.

\section{Compliance with ethical standards}

Disclosures Rachel L. Batterham reports other from Novo Nordisk, personal fees from Novo Nordisk, other from Pfizer, personal fees from Nestlé, personal fees from International Medical Press, outside the submitted work. Luca Busetto reports personal fees from Novo Nordisk, personal fees from Bruno Farmaceutici, grants from Enzymmanagement, outside the submitted work. Salvador Morales-Conde reports personal fees from BD Bard, grants and personal fees from Medtronic, personal fees from Ethicon, personal fees from Olympus, personal fees from Stryker, personal fees from BBraum, personal fees from Dipro, personal fees from Baxter, personal fees from Gore, outside the submitted work. Nicola Di Lorenzo, Stavros A. Antoniou, Daniela Godoroja, Angelo Iossa, Francesco M. Carrano, Ferdinando Agresta, Isaias Alarçon, Carmil Azran, Nicole Bouvy, M. Carmen Balaguè Ponz, Maura Buza, Catalin Copaescu, Maurizio De Luca, Dror Dicker, Angelo Di Vincenzo, Daniel M. Felsenreich, Nader K. Francis, Martin Fried, Berta Gonzalo Prats, David Goitein, Jason C.G. Halford, Jitka Herlesova, Marina Kalogridaki, Hans Ket, Giacomo Piatto, Gerhard Prager, Suzanne Pruijssers, Andrea Pucci, Shlomi Rayman, Eugenia Romano, 
Sergi Sanchez-Cordero, Ramon Vilallonga, and Gianfranco Silecchia have nothing to disclose.

Open Access This article is licensed under a Creative Commons Attribution 4.0 International License, which permits use, sharing, adaptation, distribution and reproduction in any medium or format, as long as you give appropriate credit to the original author(s) and the source, provide a link to the Creative Commons licence, and indicate if changes were made. The images or other third party material in this article are included in the article's Creative Commons licence, unless indicated otherwise in a credit line to the material. If material is not included in the article's Creative Commons licence and your intended use is not permitted by statutory regulation or exceeds the permitted use, you will need to obtain permission directly from the copyright holder. To view a copy of this licence, visit http://creativecommons.org/licenses/by/4.0/.

\section{Appendix}

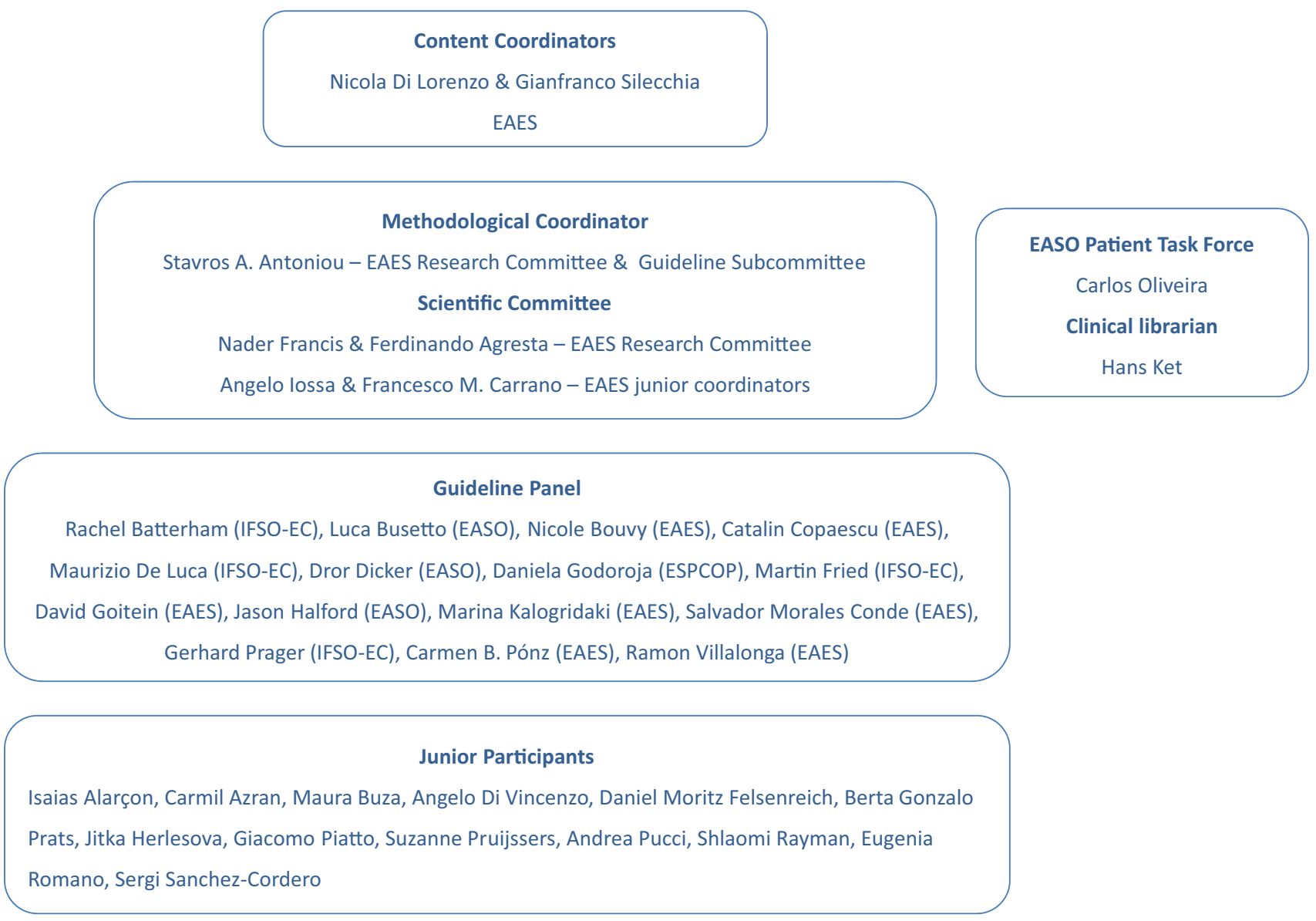




\section{References}

1. Qasim A, Turcotte M, de Souza RJ et al (2018) On the origin of obesity: identifying the biological, environmental and cultural drivers of genetic risk among human populations. Obes Rev. https://doi.org/10.1111/obr.12625

2. WHO (2012) WHO obesity and overweight. World Heal Organ Media Cent Fact Sheet No 311

3. Grundy SM, Barondess JA, Bellegie NJ et al (1991) Gastrointestinal surgery for severe obesity. Ann Intern Med. https://doi. org/10.7326/0003-4819-115-12-956

4. Sauerland S, Angrisani L, Belachew M et al (2005) Obesity surgery: Evidence-based guidelines of the European Association for Endoscopic Surgery (EAES). Surg Endosc Other Interv Tech. https://doi.org/10.1007/s00464-004-9194-1

5. SAGES (2009) SAGES guideline for clinical application of laparoscopic bariatric surgery. Surg Obes Relat Dis. https://doi. org/10.1016/j.soard.2009.01.010

6. Fried M, Hainer V, Basdevant A et al (2008) Interdisciplinary European guidelines on surgery of severe obesity. Obes Facts. https://doi.org/10.1159/000113937

7. Fried M, Yumuk V, Oppert JM et al (2017) Interdisciplinary European Guidelines on metabolic and bariatric surgery. Gastroenterol Hepatol. https://doi.org/10.14735/amgh2017487

8. Pollack A (2019) A.M.A. Recognizes obesity as a disease-The New York Times. The New York Times.

9. Schünemann H, Brożek J, Guyatt G, Oxman A (2009) GRADE handbook for grading quality of evidence and strength of recommendations. The GRADE Working Group.

10. Brouwers MC, Kho ME, Browman GP et al (2010) AGREE II: advancing guideline development, reporting and evaluation in health care. J Clin Epidemiol 63(12):1308-1311. https://doi. org/10.1016/j.jclinepi.2010.07.001

11. Liberati A, Altman DG, Tetzlaff J et al (2009) The PRISMA statement for reporting systematic reviews and meta-analyses of studies that evaluate health care interventions: explanation and elaboration. J Clin Epidemiol. https://doi.org/10.1016/j.jclin epi.2009.06.006

12. Stroup DF, Berlin JA, Morton SC, Olkin I, Williamson GDRD (2000) MOOSE guidelines for meta-analyses and systematic reviews of observational studies. JAMA

13. Norris SL, Meerpohl JJ, Akl EA, Schünemann HJ, Chen Y, Whittington C (2016) The skills and experience of GRADE methodologists can be assessed with a simple tool. J Clin Epidemiol. https://doi.org/10.1016/j.jclinepi.2016.07.001

14. Akl EA, Lang D, Jaeschke R et al (2008) Grading quality of evidence and strength of recommendations in clinical practice guidelines Part 1 of 3 . An overview of the GRADE approach and grading quality of evidence about interventions. Allergy 2009:669-677. https://doi.org/10.1111/j.1398-9995.2009.01973.x

15. Higgins JPT, Altman DG, Gøtzsche PC et al (2011) The Cochrane Collaboration's tool for assessing risk of bias in randomised trials. BMJ. https://doi.org/10.1136/bmj.d5928

16. Sterne J, Hernán M, Reeves B, et al (2016) Risk of bias in nonrandomized studies of interventions (ROBINS-I): detailed guidance. BMJ

17. Schünemann HJ, Brozek J, Guyatt GH, Oxman AD (2013) Summarizing the evidence. In: GRADE handbook. https://gdt.grade pro.org/app/handbook/handbook.html

18. Schünemann HJ, Brozek J, Guyatt GH, Oxman AD (2013) Quality of evidence. GRADE handbook. https://gdt.gradepro.org/app/ handbook/handbook.html

19. Schünemann HJ, Brozek J, Guyatt GH, Oxman AD (2013) Going from evidence to recommendations. GRADE handbook. https:// gdt.gradepro.org/app/handbook/handbook.html
20. GRADE Working Group (2015) GRADEpro guideline development tool [software]. McMaster Univ

21. O'Brien PE, Dixon JB, Laurie C et al (2006) Treatment of mild to moderate obesity with laparoscopic adjustable gastric banding or an intensive medical program. Ann Intern Med 144(9):625. https://doi.org/10.7326/0003-4819-144-9-200605020-00005

22. Dixon JB, O'Brien PE, Playfair J et al (2008) Adjustable gastric banding and conventional therapy for type 2 diabetes. JAMA. https://doi.org/10.1001/jama.299.3.316

23. Liang Z, Wu Q, Chen B, Yu P, Zhao H, Ouyang X (2013) Effect of laparoscopic Roux-en-Y gastric bypass surgery on type 2 diabetes mellitus with hypertension: a randomized controlled trial. Diabetes Res Clin Pract 101(1):50-56. https://doi.org/10.1016/j. diabres.2013.04.005

24. Wentworth JM, Playfair J, Laurie C et al (2014) Multidisciplinary diabetes care with and without bariatric surgery in overweight people: a randomised controlled trial. Lancet Diabetes Endocrinol 2(7):545-552. https://doi.org/10.1016/S2213 -8587(14)70066-X

25. Schauer PR, Kashyap SR, Wolski K et al (2012) Bariatric surgery versus intensive medical therapy in obese patients with diabetes. N Engl J Med 366(17):1567-1576. https://doi.org/10.1056/ NEJMoa1200225

26. Schauer PR, Bhatt DL, Kirwan JP et al (2017) Bariatric surgery versus intensive medical therapy for diabetes-5-year outcomes. N Engl J Med 376(7):641-651. https://doi.org/10.1056/NEJMo a1600869

27. Mingrone G, Panunzi S, De Gaetano A et al (2012) Bariatric surgery versus conventional medical therapy for type 2 diabetes. $\mathrm{N}$ Engl J Med 366(17):1577-1585. https://doi.org/10.1056/NEJMo a1200111

28. Ikramuddin S, Billington CJ, Lee W-J et al (2015) Roux-en-Y gastric bypass for diabetes (the diabetes surgery study): 2-year outcomes of a 5-year, randomised, controlled trial. Lancet Diabetes Endocrinol 3(6):413-422. https://doi.org/10.1016/S2213 $-8587(15) 00089-3$

29. Ikramuddin S, Korner J, Lee W-J et al (2013) Roux-en-Y gastric bypass vs intensive medical management for the control of type 2 diabetes, hypertension, and hyperlipidemia. JAMA 309(21):2240. https://doi.org/10.1001/jama.2013.5835

30. Mingrone G, Panunzi S, De Gaetano A et al (2015) Bariatric-metabolic surgery versus conventional medical treatment in obese patients with type 2 diabetes: 5 year follow-up of an open-label, single-centre, randomised controlled trial. Lancet 386(9997):964-973. https://doi.org/10.1016/S0140 $-6736(15) 00075-6$

31. Courcoulas AP, Goodpaster BH, Eagleton JK et al (2014) Surgical vs medical treatments for type 2 diabetes mellitus. JAMA Surg 149(7):707. https://doi.org/10.1001/jamasurg.2014.467

32. Halperin F, Ding S-A, Simonson DC et al (2014) Roux-en-Y gastric bypass surgery or lifestyle with intensive medical management in patients with type 2 diabetes. JAMA Surg 149(7):716. https://doi.org/10.1001/jamasurg.2014.514

33. Ding S-A, Simonson DC, Wewalka M et al (2015) Adjustable gastric band surgery or medical management in patients with type 2 diabetes: a randomized clinical trial. J Clin Endocrinol Metab 100(7):2546-2556. https://doi.org/10.1210/jc.2015-1443

34. Parikh M, Chung M, Sheth S et al (2014) Randomized pilot trial of bariatric surgery versus intensive medical weight management on diabetes remission in type 2 diabetic patients who do not meet NIH criteria for surgery and the role of soluble RAGE as a novel biomarker of success. Ann Surg 260(4):617-624. https:// doi.org/10.1097/SLA.0000000000000919

35. Cummings DE, Arterburn DE, Westbrook EO et al (2016) Gastric bypass surgery vs intensive lifestyle and medical intervention for type 2 diabetes: the CROSSROADS randomised controlled 
trial. Diabetologia 59(5):945-953. https://doi.org/10.1007/s0012 5-016-3903-x

36. Sjöström L (2013) Review of the key results from the Swedish Obese Subjects (SOS) trial: a prospective controlled intervention study of bariatric surgery. J Intern Med. https://doi.org/10.1111/ joim. 12012

37. Smelt HJM, Smulders JF, Gilissen LPL, Said M, Ugale S, Pouwels S (2018) Influence of Helicobacter pylori infection on gastrointestinal symptoms and complications in bariatric surgery patients: a review and meta-analysis. Surg Obes Relat Dis. https ://doi.org/10.1016/j.soard.2018.06.020

38. Mocanu V, Dang JT, Switzer N et al (2018) The effect of helicobacter pylori on postoperative outcomes in patients undergoing bariatric surgery: a systematic review and meta-analysis. Obes Surg. https://doi.org/10.1007/s11695-017-3024-8

39. Schulman AR, Abougergi MS, Thompson CCH (2017) Pylori as a predictor of marginal ulceration: a nationwide analysis. Obesity. https://doi.org/10.1002/oby.21759

40. Antoniou SA, Anastasiadou A, Antoniou GA, Granderath F-A, Kafatos A (2017) Preoperative nutritional counseling versus standard care prior to bariatric surgery: Effects on postoperative weight loss. Eur Surg Acta Chir Aust. https://doi.org/10.1007/ s10353-016-0459-4

41. Bennett S, Gostimir M, Shorr R, Mallick R, Mamazza J, Neville A (2016) The role of routine preoperative upper endoscopy in bariatric surgery: a systematic review and meta-analysis. Surg Obes Relat Dis. https://doi.org/10.1016/j.soard.2016.04.012

42. Parikh M, Liu J, Vieira D et al (2016) Preoperative endoscopy prior to bariatric surgery: a systematic review and meta-analysis of the literature. Obes Surg. https://doi.org/10.1007/s1169 5-016-2232-y

43. Dawes AJ, Maggard-Gibbons M, Maher AR et al (2016) Mental health conditions among patients seeking and undergoing bariatric surgery a meta-analysis. JAMA. https://doi.org/10.1001/ jama.2015.18118

44. De Luca M, Angrisani L, Himpens J et al (2016) Indications for surgery for obesity and weight-related diseases: position statements from the international federation for the surgery of obesity and metabolic disorders (IFSO). Obes Surg. https://doi. org/10.1007/s11695-016-2271-4

45. Mokhlesi B, Hovda MD, Vekhter B, Arora VM, Chung F, Meltzer DO (2013) Sleep-disordered breathing and postoperative outcomes after bariatric surgery: analysis of the nationwide inpatient sample. Obes Surg. https://doi.org/10.1007/s11695-013-0991-2

46. Elrashidy AA, Elsherif M, Elhag W, Abdel-Rahman RS, Abdelaziem S (2018) Does obstructive sleep apnea (OSA) increase the risk of post-operative respiratory complications after bariatric surgery? Open J Anesthesiol 08(10):255-266. https://doi. org/10.4236/ojanes.2018.810026

47. Xará D, Mendonça J, Pereira H, Santos A, Abelha FJ (2015) Adverse respiratory events after general anesthesia in patients at high risk of obstructive sleep apnea syndrome. Braz J Anesthesiol. https://doi.org/10.1016/j.bjane.2014.02.008

48. Toshniwal G, McKelvey GM, Wang H (2014) STOP-Bang and prediction of difficult airway in obese patients. J Clin Anesth. https://doi.org/10.1016/j.jclinane.2014.01.010

49. Hallowell PT, Stellato TA, Petrozzi MC et al (2007) Eliminating respiratory intensive care unit stay after gastric bypass surgery. Surgery. https://doi.org/10.1016/j.surg.2007.08.002

50. Weingarten TN, Flores AS, McKenzie JA et al (2011) Obstructive sleep apnoea and perioperative complications in bariatric patients. Br J Anaesth. https://doi.org/10.1093/bja/aeq290

51. Jensen C, Tejirian T, Lewis C, Yadegar J, Dutson E, Mehran A (2008) Postoperative CPAP and BiPAP use can be safely omitted after laparoscopic Roux-en-Y gastric bypass. Surg Obes Relat Dis. https://doi.org/10.1016/j.soard.2008.05.003
52. Proczko MA, Stepaniak PS, de Quelerij M et al (2014) STOPBang and the effect on patient outcome and length of hospital stay when patients are not using continuous positive airway pressure. J Anesth. https://doi.org/10.1007/s00540-014-1848-0

53. Kurrek MM, Cobourn C, Wojtasik Z, Kiss A, Dain SL (2011) Morbidity in patients with or at high risk for obstructive sleep apnea after ambulatory laparoscopic gastric banding. Obes Surg. https://doi.org/10.1007/s11695-011-0381-6

54. Nepomnayshy D, Hesham W, Erickson B, MacDonald J, Iorio R, Brams D (2013) Sleep apnea: is routine preoperative screening necessary? Obes Surg. https://doi.org/10.1007/s1169 5-012-0806-x

55. Shearer E, Magee CJ, Lacasia C, Raw D, Kerrigan D (2013) Obstructive sleep apnea can be safely managed in a level 2 critical care setting after laparoscopic bariatric surgery. Surg Obes Relat Dis. https://doi.org/10.1016/j.soard.2012.09.006

56. El Shobary H, Backman S, Christou N, Schricker T (2008) Use of critical care resources after laparoscopic gastric bypass: effect on respiratory complications. Surg Obes Relat Dis. https://doi. org/10.1016/j.soard.2008.02.003

57. Lyons MM, Keenan BT, Li J et al (2017) Symptomless multivariable apnea prediction index assesses obstructive sleep apnea risk and adverse outcomes in elective surgery. Sleep. https://doi. org/10.1093/sleep/zsw081

58. Grover BT, Priem DM, Mathiason MA, Kallies KJ, Thompson GP, Kothari SN (2010) Intensive care unit stay not required for patients with obstructive sleep apnea after laparoscopic Roux-enY gastric bypass. Surg Obes Relat Dis. https://doi.org/10.1016/j. soard.2009.12.006

59. Ahmad S, Nagle A, McCarthy RJ, Fitzgerald PC, Sullivan JT, Prystowsky J (2008) Postoperative hypoxemia in morbidly obese patients with and without obstructive sleep apnea undergoing laparoscopic bariatric surgery. Anesth Analg. https://doi. org/10.1213/ane.0b013e318174df8b

60. Meng L (2010) Postoperative nausea and vomiting with application of postoperative continuous positive airway pressure after laparoscopic gastric bypass. Obes Surg. https://doi.org/10.1007/ s11695-008-9741-2

61. Meurgey JH, Brown R, Woroszyl-Chrusciel A, Steier J (2018) Peri-operative treatment of sleep-disordered breathing and outcomes in bariatric patients. J Thorac Dis. https://doi. org/10.21037/jtd.2017.10.11

62. Imberti D, Baldini E, Pierfranceschi MG et al (2014) Prophylaxis of venous thromboembolism with low molecular weight heparin in bariatric surgery: a prospective, randomised pilot study evaluating two doses of parnaparin (BAFLUX study). Obes Surg. https ://doi.org/10.1007/s11695-013-1105-X

63. Steele KE, Canner J, Prokopowicz G et al (2015) The EFFORT trial: Preoperative enoxaparin versus postoperative fondaparinux for thromboprophylaxis in bariatric surgical patients: a randomized double-blind pilot trial. Surg Obes Relat Dis. https:// doi.org/10.1016/j.soard.2014.10.003

64. Kaw R, Pasupuleti V, Wayne Overby D et al (2014) Inferior vena cava filters and postoperative outcomes in patients undergoing bariatric surgery: a meta-analysis. Surg Obes Relat Dis. https:// doi.org/10.1016/j.soard.2014.04.008

65. Małczak P, Pisarska M, Piotr M, Wysocki M, Budzyński A, Pędziwiatr M (2017) Enhanced recovery after bariatric surgery: systematic review and meta-analysis. Obes Surg. https://doi. org/10.1007/s11695-016-2438-z

66. Singh PM, Panwar R, Borle A et al (2017) Efficiency and safety effects of applying ERAS protocols to bariatric surgery: a systematic review with meta-analysis and trial sequential analysis of evidence. Obes Surg. https://doi.org/10.1007/s11695-016-2442-3

67. Ng JJ, Leong WQ, Tan CS et al (2017) A multimodal analgesic protocol reduces opioid-related adverse events and improves 
patient outcomes in laparoscopic sleeve gastrectomy. Obes Surg. https://doi.org/10.1007/s11695-017-2790-7

68. Bamgbade OA, Oluwole O, Khaw RR (2017) Perioperative analgesia for fast-track laparoscopic bariatric surgery. Obes Surg. https://doi.org/10.1007/s11695-017-2562-4

69. Ziemann-Gimmel P, Hensel P, Koppman J, Marema R (2013) Multimodal analgesia reduces narcotic requirements and antiemetic rescue medication in laparoscopic Roux-en-Y gastric bypass surgery. Surg Obes Relat Dis. https://doi.org/10.1016/j. soard.2013.02.003

70. El Sherif FA, Othman AH, Abd El-Rahman AM, Taha O (2016) Effect of adding intrathecal morphine to a multimodal analgesic regimen for postoperative pain management after laparoscopic bariatric surgery: a prospective, double-blind, randomized controlled trial. Br J Pain. https://doi.org/10.1177/204946371666890 4

71. Na HS, Oh AY, Ryu JH et al (2018) Intraoperative nefopam reduces acute postoperative pain after laparoscopic gastrectomy: a prospective randomized study. J Gastrointest Surg. https://doi. org/10.1007/s11605-018-3681-5

72. Feld JM, Laurito CE, Beckerman M, Vincent J, Hoffman WE (2003) Non-opioid analgesia improves pain relief and decreases sedation after gastric bypass surgery. Can J Anesth. https://doi. org/10.1007/BF03021029

73. Song K, Melroy MJ, Whipple OC (2014) Optimizing multimodal analgesia with intravenous acetaminophen and opioids in postoperative bariatric patients. Pharmacotherapy. https://doi. org/10.1002/phar.1517

74. El Sayed M, Abdelsamad A, Amer A (2017) Shorter postanesthesia care unit stay with dexmedetomidine infusion during laparoscopic bariatric surgery: a randomized controlled trial. Res Opin Anesth Intensive Care. https://doi.org/10.4103/roaic.roaic_103_16

75. De Oliveira GS, Duncan K, Fitzgerald P, Nader A, Gould RW, McCarthy RJ (2014) Systemic lidocaine to improve quality of recovery after laparoscopic bariatric surgery: a randomized double-blinded placebo-controlled trial. Obes Surg. https://doi. org/10.1007/s11695-013-1077-x

76. Horsley R, Vogels E, McField D et al (2016) Multimodal postoperative pain control is effective and reduces narcotic use after laparoscopic Roux-en-Y gastric bypass (LRYGB). Surg Obes Relat Dis. https://doi.org/10.1016/j.soard.2016.08.145

77. Gill RS, Majumdar SR, Rueda-Clausen CF et al (2016) Comparative effectiveness and safety of gastric bypass, sleeve gastrectomy and adjustable gastric banding in a population-based bariatric program: prospective cohort study. Can J Surg 59(4):233-241. https://doi.org/10.1503/cjs.013315

78. Angrisani L, Cutolo PP, Formisano G, Nosso G, Vitolo G (2013) Laparoscopic adjustable gastric banding versus Roux-en-Y gastric bypass: 10 -year results of a prospective, randomized trial. Surg Obes Relat Dis 9(3):405-413. https://doi.org/10.1016/j. soard.2012.11.011

79. Campos GM (2011) Better weight loss, resolution of diabetes, and quality of life for laparoscopic gastric bypass vs banding. Arch Surg 146(2):149. https://doi.org/10.1001/archsurg.2010.316

80. Courcoulas AP, King WC, Belle SH et al (2018) Seven-year weight trajectories and health outcomes in the longitudinal assessment of bariatric surgery (LABS) study. JAMA Surg 153(5):427. https://doi.org/10.1001/jamasurg.2017.5025

81. Dogan K, Gadiot RPM, Aarts EO et al (2015) Effectiveness and safety of sleeve gastrectomy, gastric bypass, and adjustable gastric banding in morbidly obese patients: a multicenter, retrospective, matched cohort study. Obes Surg 25(7):1110-1118. https:// doi.org/10.1007/s11695-014-1503-8

82. Flint R (2015) A comparison of laparoscopic adjustable gastric band and laparoscopic sleeve gastrectomy: a single surgeon's experience. N Z Med J 128:56
83. Lee SK, Heo Y, Park J-M et al (2016) Roux-en-Y gastric bypass vs sleeve gastrectomy vs gastric banding: the first multicenter retrospective comparative cohort study in obese Korean patients. Yonsei Med J 57(4):956. https://doi.org/10.3349/ ymj.2016.57.4.956

84. Nguyen NT, Slone JA, Nguyen X-MT, Hartman JS, Hoyt DB (2009) A prospective randomized trial of laparoscopic gastric bypass versus laparoscopic adjustable gastric banding for the treatment of morbid obesity. Trans Am Surg Assoc 127:262-272. https://doi.org/10.1097/SLA.0b013e3181b92480

85. Nguyen NT, Kim E, Vu S, Phelan M (2018) Ten-year outcomes of a prospective randomized trial of laparoscopic gastric bypass versus laparoscopic gastric banding. Ann Surg 268(1):106-113. https://doi.org/10.1097/SLA.0000000000002348

86. Novikov AA, Afaneh C, Saumoy M et al (2018) Endoscopic sleeve gastroplasty, laparoscopic sleeve gastrectomy, and laparoscopic band for weight loss: how do they compare? J Gastrointest Surg 22(2):267-273. https://doi.org/10.1007/s11605-017-3615-7

87. Sabbagh C, Verhaeghe P, Dhahri A et al (2010) Two-year results on morbidity, weight loss and quality of life of sleeve gastrectomy as first procedure, sleeve gastrectomy after failure of gastric banding and gastric banding. Obes Surg 20(6):679-684. https:// doi.org/10.1007/s11695-009-0007-4

88. Schouten R, Wiryasaputra DC, van Dielen FMH, van Gemert WG, Greve JWM (2010) Long-term results of bariatric restrictive procedures: a prospective study. Obes Surg 20(12):1617-1626. https://doi.org/10.1007/s11695-010-0211-2

89. Schouten R, Wiryasaputra DCMS, van Dielen FMH, van Gemert WG, Greve JWM (2011) Influence of reoperations on longterm quality of life after restrictive procedures: a prospective study. Obes Surg 21(7):871-879. https://doi.org/10.1007/s1169 5-010-0350-5

90. Kang JH, Le QA (2017) Effectiveness of bariatric surgical procedures: a systematic review and network meta-analysis of randomized controlled trials. Medicine. https://doi.org/10.1097/ MD.0000000000008632

91. Kodama S, Fujihara K, Horikawa C et al (2018) Network metaanalysis of the relative efficacy of bariatric surgeries for diabetes remission. Obes Rev. https://doi.org/10.1111/obr.12751

92. Grubnik VV, Ospanov OB, Namaeva KA, Medvedev OV, Kresyun MS (2016) Randomized controlled trial comparing laparoscopic greater curvature plication versus laparoscopic sleeve gastrectomy. Surg Endosc. https://doi.org/10.1007/s0046 4-015-4373-9

93. Bužga M, Švagera Z, Tomášková H, Hauptman K, Holéczy P (2017) Metabolic effects of sleeve gastrectomy and laparoscopic greater curvature plication: an 18-month prospective, observational, open label study. Obes Surg. https://doi.org/10.1007/ s11695-017-2779-2

94. Shikora SA, Mahoney CB (2015) Clinical benefit of gastric staple line reinforcement (SLR) in gastrointestinal surgery: a metaanalysis. Obes Surg. https://doi.org/10.1007/s11695-015-1703-x

95. Wang Z, Dai X, Xie H, Feng J, Li Z, Lu Q (2016) The efficacy of staple line reinforcement during laparoscopic sleeve gastrectomy: a meta-analysis of randomized controlled trials. Int J Surg. https ://doi.org/10.1016/j.jisu.2015.12.007

96. Gagner M, Hutchinson C, Rosenthal R (2016) Fifth international consensus conference: current status of sleeve gastrectomy. Surg Obes Relat Dis. https://doi.org/10.1016/j.soard.2016.01.022

97. Wang Y, Yi XY, Gong L, Li Q, Zhang J, Wang Z (2018) The effectiveness and safety of laparoscopic sleeve gastrectomy with different sizes of bougie calibration: a systematic review and meta-analysis. Int J Surg. https://doi.org/10.1016/j. ijsu.2017.12.005

98. McGlone ER, Gupta AK, Reddy M, Khan OA (2018) Antral resection versus antral preservation during laparoscopic sleeve 
gastrectomy for severe obesity: systematic review and metaanalysis. Surg Obes Relat Dis. https://doi.org/10.1016/j.soard .2018.02.021

99. Gagner M, Deitel M, Erickson AL, Crosby RD (2013) Survey on laparoscopic sleeve gastrectomy (LSG) at the fourth international consensus summit on sleeve gastrectomy. Obes Surg. https://doi. org/10.1007/s11695-013-1040-x

100. Li J, Lai D, Wu D (2016) Laparoscopic Roux-en-Y gastric bypass versus laparoscopic sleeve gastrectomy to treat morbid obesity-related comorbidities: a systematic review and metaanalysis. Obes Surg 26(2):429-442. https://doi.org/10.1007/ s11695-015-1996-9

101. Osland E, Yunus RM, Khan S, Alodat T, Memon B, Memon MA (2016) Postoperative early major and minor complications in laparoscopic vertical sleeve gastrectomy (LVSG) versus laparoscopic Roux-en-Y gastric bypass (LRYGB) procedures: a metaanalysis and systematic review. Obes Surg 26(10):2273-2284. https://doi.org/10.1007/s11695-016-2101-8

102. Osland E, Yunus RM, Khan S, Memon B, Memon MA (2016) Late postoperative complications in laparoscopic sleeve gastrectomy (LVSG) versus laparoscopic Roux-en-y gastric bypass (LRYGB). Surg Laparosc Endosc Percutan Tech 26(3):193-201. https://doi.org/10.1097/SLE.0000000000000279

103. Peterli R, Wölnerhanssen BK, Peters T et al (2018) Effect of laparoscopic sleeve gastrectomy vs laparoscopic Roux-en-Y gastric bypass on weight loss in patients with morbid obesity. JAMA 319(3):255. https://doi.org/10.1001/jama.2017.20897

104. Salminen P, Helmiö M, Ovaska J et al (2018) Effect of laparoscopic sleeve gastrectomy vs laparoscopic Roux-en-Y gastric bypass on weight loss at 5 years among patients with morbid obesity. JAMA 319(3):241. https://doi.org/10.1001/jama.2017.20313

105. Angrisani L, Santonicola A, Iovino P et al (2017) Bariatric surgery and endoluminal procedures: IFSO worldwide survey 2014. Obes Surg. https://doi.org/10.1007/s11695-017-2666-x

106. Polega JR, Barreto TW, Kemmeter KD, Koehler TJ, Davis AT, Kemmeter PR (2017) A matched cohort study of laparoscopic biliopancreatic diversion with duodenal switch and sleeve gastrectomy performed by one surgeon. Surg Obes Relat Dis. https ://doi.org/10.1016/j.soard.2016.10.023

107. Sucandy I, Titano J, Bonanni F, Antanavicius G (2014) Comparison of vertical sleeve gastrectomy versus biliopancreatic diversion. N Am J Med Sci. https://doi.org/10.4103/1947-2714.12586 5

108. Hedberg J, Sundbom M (2012) Superior weight loss and lower HbA1c 3 years after duodenal switch compared with Roux-en-Y gastric bypass: a randomized controlled trial. Surg Obes Relat Dis. https://doi.org/10.1016/j.soard.2012.01.014

109. Laurenius A, Taha O, Maleckas A, Lönroth H, Olbers T (2010) Laparoscopic biliopancreatic diversion/duodenal switch or laparoscopic Roux-en-Y gastric bypass for super-obesity-weight loss versus side effects. Surg Obes Relat Dis 6(4):408-414. https ://doi.org/10.1016/j.soard.2010.03.293

110. Søvik TT, Taha O, Aasheim ET et al (2010) Randomized clinical trial of laparoscopic gastric bypass versus laparoscopic duodenal switch for superobesity. Br J Surg. https://doi.org/10.1002/ bjs. 6802

111. Sudan R, Jain-Spangler K (2018) Tailoring bariatric surgery: sleeve gastrectomy, Roux-en-Y gastric bypass and biliopancreatic diversion with duodenal switch. J Laparoendosc Adv Surg Tech. https://doi.org/10.1089/lap.2018.0397

112. Mahawar KK, Himpens J, Shikora SA et al (2018) The first consensus statement on one anastomosis/mini gastric bypass (OAGB/MGB) using a modified delphi approach. Obes Surg 28(2):303-312. https://doi.org/10.1007/s11695-017-3070-2

113. Lee WJ, Yu PJ, Wang W, Chen TC, Wei PL, Te HM (2005) Laparoscopic Roux-en-Y versus mini-gastric bypass for the treatment of morbid obesity: a prospective randomized controlled clinical trial. Ann Surg. https://doi.org/10.1097/01.sla.0000167762 .46568 .98

114. Ruiz-Tovar J, Carbajo MA, Jimenez JM et al (2019) Long-term follow-up after sleeve gastrectomy versus Roux-en-Y gastric bypass versus one-anastomosis gastric bypass: a prospective randomized comparative study of weight loss and remission of comorbidities. Surg Endosc. https://doi.org/10.1007/s0046 4-018-6307-9

115. Quan Y, Huang A, Ye M et al (2015) Efficacy of laparoscopic mini gastric bypass for obesity and type 2 diabetes mellitus: a systematic review and meta-analysis. Gastroenterol Res Pract. https://doi.org/10.1155/2015/152852

116. Magouliotis DE, Tasiopoulou VS, Svokos AA, Svokos KA, Sioka E, Zacharoulis D (2017) One-anastomosis gastric bypass versus sleeve gastrectomy for morbid obesity: a systematic review and meta-analysis. Obes Surg. https://doi.org/10.1007/s1169 5-017-2807-2

117. Wang FG, Yu ZP, Yan WM, Yan M, Song MM (2017) Comparison of safety and effectiveness between laparoscopic mini-gastric bypass and laparoscopic sleeve gastrectomy: a meta-analysis and systematic review. Medicine. https://doi.org/10.1097/MD.00000 00000008924

118. Seetharamaiah S, Tantia O, Goyal G et al (2017) LSG vs OAGB-1 Year Follow-up Data-a Randomized Control Trial. Obes Surg. https://doi.org/10.1007/s11695-016-2403-X

119. Darabi S, Talebpour M, Zeinoddini A, Heidari R (2013) Laparoscopic gastric plication versus mini-gastric bypass surgery in the treatment of morbid obesity: a randomized clinical trial. Surg Obes Relat Dis. https://doi.org/10.1016/j.soard.2013.07.012

120. Cottam A, Cottam D, Medlin W et al (2016) A matched cohort analysis of single anastomosis loop duodenal switch versus Roux-en-Y gastric bypass with 18-month follow-up. Surg Endosc. https://doi.org/10.1007/s00464-015-4707-7

121. Surve A, Zaveri H, Cottam D, Belnap LG, Cottam A, Cottam S (2017) A retrospective comparison of biliopancreatic diversion with duodenal switch with single anastomosis duodenal switch (SIPS-stomach intestinal pylorus sparing surgery) at a single institution with two year follow-up. Surg Obes Relat Dis. https ://doi.org/10.1016/j.soard.2016.11.020

122. Lee WJ, Almulaifi AM, Tsou JJ, Ser KH, Lee YC, Chen SC (2015) Duodenal-jejunal bypass with sleeve gastrectomy versus the sleeve gastrectomy procedure alone: the role of duodenal exclusion. Surg Obes Relat Dis. https://doi.org/10.1016/j.soard .2014.12.017

123. Angrisani L, Santonicola A, Iovino P et al (2018) IFSO Worldwide survey 2016: Primary, endoluminal, and revisional procedures. Obes Surg. https://doi.org/10.1007/s11695-018-3450-2

124. Brethauer SA, Kothari S, Sudan R et al (2014) Systematic review on reoperative bariatric surgery American Society for Metabolic and Bariatric Surgery Revision Task Force. Surg Obes Relat Dis. https://doi.org/10.1016/j.soard.2014.02.014

125. Bonouvrie DS, Uittenbogaart M, Luijten AAPM, van Dielen FMH, Leclercq WKG (2019) Lack of standard definitions of primary and secondary (non)responders after primary gastric bypass and gastric sleeve: a systematic review. Obes Surg. https ://doi.org/10.1007/s11695-018-3610-4

126. Yumuk V, Tsigos C, Fried M et al (2015) European guidelines for obesity management in adults. Obes Facts. https://doi. org/10.1159/000442721

127. Inabnet WB, Belle SH, Bessler M et al (2010) Comparison of 30-day outcomes after non-LapBand primary and revisional bariatric surgical procedures from the Longitudinal Assessment of Bariatric Surgery study. Surg Obes Relat Dis. https://doi. org/10.1016/j.soard.2009.10.007 
128. Rudolph A, Hilbert A (2013) Post-operative behavioural management in bariatric surgery: a systematic review and metaanalysis of randomized controlled trials. Obes Rev. https://doi. org/10.1111/obr.12013

129. Magouliotis DE, Tasiopoulou VS, Svokos AA et al (2017) Ursodeoxycholic acid in the prevention of gallstone formation after bariatric surgery: an updated systematic review and meta-analysis. Obes Surg. https://doi.org/10.1007/s11695-017-2924-y

130. Li Z, Zhou X, Fu W (2018) Vitamin D supplementation for the prevention of vitamin $\mathrm{D}$ deficiency after bariatric surgery: a systematic review and meta-analysis. Eur J Clin Nutr. https://doi. org/10.1038/s41430-017-0059-9

131. Ying WCV, Song SH, Khan K et al (2015) Prophylactic PPI help reduce marginal ulcers after gastric bypass surgery: a systematic review and meta-analysis of cohort studies. Surg Endosc. https:// doi.org/10.1007/s00464-014-3794-1

132. Stewart F, Avenell A (2016) Behavioural interventions for severe obesity before and/or after bariatric surgery: a systematic review and meta-analysis. Obes Surg. https://doi.org/10.1007/s1169 5-015-1873-6

133. Basbug A, Ellibeş Kaya A, Dogan S, Pehlivan M, Goynumer G (2018) Does pregnancy interval after laparoscopic sleeve gastrectomy affect maternal and perinatal outcomes? J Matern Fetal Neonatal Med 32(22):3764-3770

134. Crusell M, Nilas L, Svare J, Lauenborg J (2016) A Time interval of more than 18 months between a pregnancy and a Roux-en-Y gastric bypass increases the risk of iron deficiency and anaemia in pregnancy. Obes Surg. https://doi.org/10.1007/s1169 5-016-2130-3

135. Rasteiro C, Araújo C, Cunha $S$ et al (2018) Influence of time interval from bariatric surgery to conception on pregnancy and perinatal outcomes. Obes Surg. https://doi.org/10.1007/s1169 5-018-3395-5

136. Rottenstreich A, Levin G, Kleinstern G, Rottenstreich M, Elchalal U, Elazary R (2018) The effect of surgery-to-conception interval on pregnancy outcomes after sleeve gastrectomy. Surg Obes Relat Dis. https://doi.org/10.1016/j.soard.2018.09.485

137. Stentebjerg LL, Andersen LLT, Renault K, Støving RK, Jensen DM (2017) Pregnancy and perinatal outcomes according to surgery to conception interval and gestational weight gain in women with previous gastric bypass. J Matern Neonatal Med. https://doi. org/10.1080/14767058.2016.1208746

138. Yau PO, Parikh M, Saunders JK, Chui P, Zablocki T, Welcome AU (2017) Pregnancy after bariatric surgery: the effect of timeto-conception on pregnancy outcomes. Surg Obes Relat Dis. https://doi.org/10.1016/j.soard.2017.07.015

139. Jirapinyo P, Haas AV, Thompson CC (2018) Effect of the Duodenal-jejunal bypass liner on glycemic control in patients with type 2 diabetes with obesity: a meta-analysis with secondary analysis on weight loss and hormonal changes. Diabetes Care. https://doi. org/10.2337/dc17-1985/-/DC1

140. Thompson CC, Dayyeh BKA, Kushnir V et al (2018) Aspiration therapy for the treatment of obesity: 2-4 year results of the PATHWAY multicenter randomized controlled trial. Surg Obes Relat Dis 14(11):S4-S5. https://doi.org/10.1016/j.soard .2018.09.018

141. Busetto L, Torres AJ, Morales S et al (2015) Impact of Abiliti ${ }^{\circledR}$ sensor-based feedback on eating behavior, physical activity and weight-loss in obese patients. Obes Surg 28(6):1766-1774

142. Horbach T, Thalheimer A, Seyfried F, Eschenbacher F, Schuhmann P, Meyer G (2015) abiliti ${ }^{\circledR}$ closed-loop gastric electrical stimulation system for treatment of obesity: clinical results with a 27-month follow-up. Obes Surg. https://doi.org/10.1007/s1169 $5-015-1620-z$
143. Torres A, Meyer G, Conde SM, et al (2015) Closed-loop gastric electrical stimulation (CLGES) with behavioral feedback for treatment of obesity: prospective multicenter trial with 18 month follow-up. Obes Surg

144. Sarr MG, Billington CJ, Brancatisano R et al (2012) The EMPOWER study: randomized, prospective, double-blind, multicenter trial of vagal blockade to induce weight loss in morbid obesity. Obes Surg. https://doi.org/10.1007/s11695-012-0751-8

145. Ikramuddin S, Blackstone RP, Brancatisano A et al (2014) Effect of reversible intermittent intra-abdominal vagal nerve blockade on morbid obesity: the ReCharge randomized clinical trial. JAMA. https://doi.org/10.1001/jama.2014.10540

146. Shikora SA, Wolfe BM, Apovian CM et al (2015) Sustained blockade weight loss with vagal nerve but not with sham: 18-month results of the ReCharge trial. J Obes. https://doi. org/10.1155/2015/365604

147. Apovian CM, Shah SN, Wolfe BM et al (2017) Two-year outcomes of vagal nerve blocking (vBloc) for the treatment of obesity in the ReCharge trial. Obes Surg. https://doi.org/10.1007/ s11695-016-2325-7

148. van Baar ACG, Nieuwdorp M, Holleman F et al (2018) Duodenal mucosal resurfacing elicits improvement in glycemic and hepatic parameters in type 2 diabetes-one-year multicenter study results. Diabetes 67(Supplement 1):1137. https://doi. org/10.2337/db18-1137-P

149. Miller K, Turró R, Greve JW, Bakker CM, Buchwald JN, Espinós JC (2017) MILEPOST multicenter randomized controlled trial: 12-month weight loss and satiety outcomes after poseSMvs, medical therapy. Obes Surg. https://doi.org/10.1007/s1169 5-016-2295-9

150. Sullivan S, Swain JM, Woodman G et al (2017) Randomized sham-controlled trial evaluating efficacy and safety of endoscopic gastric plication for primary obesity: the ESSENTIAL trial. Obesity. https://doi.org/10.1002/oby.21702

151. López-Nava G, Bautista-Castaño I, Jimenez A, De Grado T, Fernandez-Corbelle JP (2015) The primary obesity surgery endolumenal (POSE) procedure: one-year patient weight loss and safety outcomes. Surg Obes Relat Dis. https://doi.org/10.1016/j.soard 2014.09.026

152. Sharaiha RZ, Kumta NA, Saumoy M et al (2017) Endoscopic sleeve gastroplasty significantly reduces body mass index and metabolic complications in obese patients. Clin Gastroenterol Hepatol. https://doi.org/10.1016/j.cgh.2016.12.012

153. Ahishali E (2018) Endoscopic sleeve gastroplasty for obesity: a multicenter study of 248 patients with 24 months follow-up. Turkish J Gastroenterol. https://doi.org/10.5152/tjg.2018.18050 1

154. Lopez-Nava G, Galvão M, Bautista-Castaño I, Fernandez-Corbelle J, Trell M, Lopez N, (2017) Endoscopic sleeve gastroplasty for obesity treatment: two years of experience. Arq Bras Circ Dig 30(1):18-20. https://doi.org/10.1590/0102-6720201700010006

155. Lopez-Nava G, Galvao M, Bautista-Castaño I, FernandezCorbelle J, Trell M (2016) Endoscopic sleeve gastroplasty with 1-year follow-up: factors predictive of success. Endosc Int Open. https://doi.org/10.1055/s-0041-110771

156. Alqahtani A, Al-Darwish A, Mahmoud AE, Alqahtani YA, Elahmedi M (2019) Short-term outcomes of endoscopic sleeve gastroplasty in 1000 consecutive patients. Gastrointest Endosc. https://doi.org/10.1016/j.gie.2018.12.012

Publisher's Note Springer Nature remains neutral with regard to jurisdictional claims in published maps and institutional affiliations. 


\section{Affiliations}

Nicola Di Lorenzo ${ }^{1}$ - Stavros A. Antoniou ${ }^{2,3}$ - Rachel L. Batterham ${ }^{4,5} \cdot$ Luca Busetto $^{6}$ - Daniela Godoroja ${ }^{7}$. Angelo lossa $^{8}$. Francesco M. Carrano ${ }^{9}$. Ferdinando Agresta ${ }^{10}$. Isaias Alarçon ${ }^{11}$. Carmil Azran ${ }^{12}$. Nicole Bouvy ${ }^{13}$. Carmen Balaguè Ponz ${ }^{14}$. Maura Buza ${ }^{15}$. Catalin Copaescu ${ }^{15}$. Maurizio De Luca ${ }^{16}$. Dror Dicker ${ }^{17}$.

Angelo Di Vincenzo ${ }^{6}$. Daniel M. Felsenreich ${ }^{18} \cdot$ Nader K. Francis $^{19} \cdot$ Martin Fried $^{20} \cdot$ Berta Gonzalo Prats $^{14}$. David Goitein ${ }^{21,22}$. Jason C. G. Halford ${ }^{23}$. Jitka Herlesova ${ }^{20}$. Marina Kalogridaki ${ }^{24}$. Hans Ket ${ }^{25}$.

Salvador Morales-Conde ${ }^{11}$. Giacomo Piatto ${ }^{16}$. Gerhard Prager ${ }^{18}$. Suzanne Pruijssers ${ }^{13}$. Andrea Pucci ${ }^{4,5}$. Shlomi Rayman ${ }^{21,22} \cdot$ Eugenia Romano $^{23} \cdot$ Sergi Sanchez-Cordero ${ }^{26} \cdot$ Ramon Vilallonga $^{27} \cdot$ Gianfranco Silecchia $^{8}$

\section{Gianfranco Silecchia}

gianfranco.silecchia@uniroma1.it

1 Department of Surgical Sciences, University of Rome "Tor Vergata", Rome, Italy

2 Department of Surgery, European University of Cyprus, Nicosia, Cyprus

3 Department of Surgery, Mediterranean Hospital of Cyprus, Limassol, Cyprus

4 Centre for Obesity Research, University College London, London, UK

5 Biomedical Research Centre, National Institute of Health Research, London, UK

6 Internal Medicine 3, Department of Medicine, DIMED, Center for the Study and the Integrated Treatment of Obesity, University Hospital of Padua, Padua, Italy

7 Department of Anesthesiology, Ponderas Academic Hospital Regina Maria, Bucharest, Romania

8 Department of Medical-Surgical Sciences and Biotechnologies, Faculty of Pharmacy and Medicine, "La Sapienza" University of Rome-Polo Pontino, Bariatric Centre of Excellence IFSO-EC, Via F. Faggiana 1668, 04100 Latina, Italy

9 Department of Endocrine and Metabolic Surgery, University of Insubria, Ospedale di Circolo and Fondazione Macchi, ASST Sette Laghi, Varese, Italy

10 Department of General Surgery, ULSS5 del Veneto, Adria, Italy

11 Unit of Innovation in Minimally Invasive Surgery, Department of General and Digestive Surgery, University Hospital "Virgen del Rocío", 41010 Sevilla, Spain

12 Herzliya Medical Center, Herzliya, Israel

13 Department of Surgery, Maastricht University Medical Centre, Maastricht, The Netherlands
14 Hospital Sant Pau, UAB, Barcelona, Spain

15 Department of General Surgery, Ponderas Academic Hospital Regina Maria, Bucharest, Romania

16 Division of General Surgery, Castelfranco and Montebelluna Hospitals, Treviso, Italy

17 Department of Internal Medicine D, Hasharon Hospital, Rabin Medical Center, Sackler School of Medicine, Tel Aviv University, Tel Aviv, Israel

18 Division of General Surgery, Department of Surgery, Vienna Medical University, Vienna, Austria

19 Department of General Surgery, Yeovil District Hospital NHS Foundation Trust, Yeovil, UK

20 Center for Treatment of Obesity and Metabolic Disorders, OB Klinika, Prague, Czech Republic

21 Sackler School of Medicine, Tel Aviv University, Tel Aviv, Israel

22 Department of Surgery C, Chaim Sheba Medical Center, Ramat Gan, Israel

23 Department of Psychological Sciences, Institute of Psychology, Health and Society, University of Liverpool, Liverpool, UK

24 Emergency Department, General Hospital of Attica "KAT", Athens, Greece

25 VU Amsterdam, Amsterdam, Netherlands

26 General Surgery Department, Consorci Sanitari de L'Anoia, Barcelona, Spain

27 Endocrine, Metabolic and Bariatric Unit, General Surgery Department, Vall D'Hebron University Hospital, Center of Excellence for the EAC-BC, Universitat Autònoma de Barcelona, Barcelona, Spain 